\title{
Prediction of ply crack evolution and stiffness degradation in multidirectional symmetric laminates under multiaxial stress states
}

\author{
John Montesano ${ }^{\mathrm{a},}{ }^{*}$, Brent McCleave ${ }^{\mathrm{a}}$, Chandra Veer Singh b,c \\ a Dept. of Mechanical \& Mechatronics Engineering, University of Waterloo, 200 University Ave. West, Waterloo, Canada N2L \\ $3 \mathrm{G} 1$ \\ ${ }^{b}$ Dept. of Materials Science and Engineering, University of Toronto, 184 College St., Suite 140, Toronto, Canada, M5S 3E4 \\ ${ }^{c}$ Dept. of Mechanical and Industrial Engineering, University of Toronto, 5 King's College Road, Toronto, Canada, M5S 3G8 \\ ${ }^{*}$ Corresponding Author: Tel.: +1 (416) 888-4567, ext. 38086, Email: john.montesano@uwaterloo.ca
}

\begin{abstract}
A comprehensive study was performed to assess the influence of microscopic ply crack interactions on crack surface opening (COD) and sliding displacements (CSD) for arbitrary plies in general symmetric multidirectional laminates under multiaxial stresses. Based on a generated database, general unified expressions for determining both CODs and CSDs at various crack densities were developed and used with a multiscale damage-based model to predict stiffness degradation and ply crack evolution for crossply, angle-ply and quasi-isotropic laminates. The predicted elastic properties for laminates containing cracks in individual plies, as well as simultaneous cracks in multiple plies, were found to correlate well with data from independent finite element analysis, while crack density predictions were validated with available experimental data. The developed unified expressions have increased the robustness and range of applicability of our damage-based multiscale model. Meanwhile, the ability of the model to predict simultaneous cracking in multiple plies and both intra-ply and inter-ply crack interactions for laminates under combines stresses is regarded as advantageous. The model can be invoked to efficiently predict ply crack evolution in laminates, and when combined with a suitable delamination model may be used as a design tool to assess the long-term durability of critical load-bearing structures.
\end{abstract}

Keywords: A. Laminates; B. Transverse cracking; C. Micro-mechanics; C. Damage mechanics.

\section{Introduction}

The optimal use of multidirectional laminates for critical load-bearing structures requires an enhanced understanding of their complex failure processes. In particular, the consideration of subcritical intra-ply 
crack evolution predominantly driven by in-plane transverse and shear stresses within the plies is important for accurately assessing the long-term durability of many practical structures. These localized ply cracks, which span the ply thickness and are typically oriented along the respective fiber directions [1], tend to form in multiple plies simultaneously as the structure is loaded [2], [3]. The progressive nature of damage involves multiplication of these cracks, where the main outcome is a reduction of the laminate elastic properties during the structure's service life. As the crack density within a particular ply increases, the local stress fields between cracks begin to interact, causing the crack surface displacements to decrease (i.e., the so-called crack shielding effect) [4]. This intra-ply crack interaction phenomena directly influences the degradation of the laminate elastic properties. Another important characteristic of the laminate ply crack evolution process is the constraining effect between adjacent plies, which also directly influences local ply stresses, crack surface displacements (i.e., inter-ply crack interactions), and stiffness degradation [4]. Furthermore, although sub-critical in nature ply cracks typically cause the onset of critical damage modes such as delamination (i.e., inter-ply cracking), where a complex crack interaction scenario can ensue on multiple length scales [5]-[10]. Thus, it is important to asses the progressive nature of ply cracking in multidirectional laminates.

A number of studies have made important contributions on the subject of laminate ply crack evolution, where predicted results from various damage-based models have been reported (e.g., see reviews in Refs. [11]-[13]). For the purposes of this paper, these models can be grouped into two main categories: those based on closed-form analytical expressions for local ply stresses or displacements (i.e., micromechanics), and those based on continuum approaches.

Models in the first category focus mainly on determining the local stress or displacement fields between adjacent ply cracks using closed-form analytical expressions. Many of these models described intra-ply crack interaction and/or the associated stiffness degradation using a shear-lag or modified shearlag approach [14]-[22]. A general drawback with existing 1D or 2D shear-lag models is that they are limited to cross-ply laminates, while modified shear-lag models have been applied to multidirectional laminates but do not account for 3D effects. A full 3D analysis is required to accurately capture ply 
constraining effects which directly influence the stress and displacement fields between ply cracks. Variational models developed by Nairn and Hashin [23]-[26], the stress transfer model by McCartney [27], and the discrete damage mechanics model by Barbero et al. [28], [29] also have similar drawbacks. Garcia et al. [30] developed a 3D numerical model for predicting the onset of first ply crack and Berthelot and LeCorre [31] developed an analytical model for predicting stiffness degradation during cyclic loading; however, only cross-ply laminates are considered in both studies. Loukil et al. [12] have recently reported that the shear-lag and variational based models have limited accuracy when evaluating crack surface displacements. In general, these models are formulated for a particular laminate stacking sequence (often cross-ply), they are quite complex and cannot be easily implemented into finite element (FE) software which limits their application. These models also only consider cracking in one ply without capturing ply constraining effects or inter-ply crack interactions. In a recent study by Carraro and Quaresimin [13], an "optimal" shear lag model based on the work by Nairn and Mendels [32] was developed to predict stiffness degradation in terms of ply crack density for symmetric multidirectional laminates. The model considers interactions between cracks in multiple plies and only requires few parameters for calibration which is seen as a notable improvement over existing shear lag models; however, it has not been used for predicting crack evolution.

Models in the second category predict continuum laminate property degradation using a multiscale approach, where local displacements or stresses between adjacent ply cracks are typically considered to define the corresponding damage parameters. Gudmundson [33], [34] considered crack surface opening displacements (COD) and sliding displacements (CSD) for this purpose, and applied an analytical model to laminates with general stacking sequences without accounting for ply constraining effects. Similarly, Varna and co-workers [35], [36], [12] used a global-local approach based on ply COD derived from meso-mechanical FE models, and was used to predict crack evolution in $90^{\circ}$ plies of uniaxially loaded multidirectional laminates. Intra-ply crack interactions were modeled; however, simultaneous cracking in multiple plies was not considered. Singh and Talreja [37], [38] also employed 3D meso-mechanical FE models to evaluate CODs and predict stiffness degradation of multidirectional laminates, while 
accounting for intra-ply crack interactions, ply constraining effects, and simultaneous cracking in multiple plies. Ghayour et al. [39] employed a similar approach where 2D meso-mechanical FE models of laminates containing cracks were used to calibrate a damage-based continuum model to predict crack evolution and stiffness degradation of multidirectional laminates. Additional studies have reported similar models based on meso-mechanical FE analysis [40], [41]. Pineda and Waas [42] utilized an analytical model based on CODs within a continuum framework to evaluate stiffness degradation of multidirectional laminates. The model is capable of simulating multi-ply cracking scenarios; however, the ply constraining effect on CODs is not strictly accounted for. Santhosh et al. [43] developed an empirical micro damage-based model to predict matrix damage evolution and stiffness degradation in laminates under multiaxial loads. The advantages with continuum-based models is their ability to directly link the effects of microscopic ply cracks with laminate elastic properties. In addition, they are easily implemented into commercial FE software for assessing durability of structures, and are applicable for general laminate stacking sequences as they can account for ply constraining effects and simultaneous ply cracking scenarios. A drawback with many existing models is the limited ability to predict ply crack evolution in laminates under multiaxial stress states, which is critical for accurately predicting the longterm durability for practical structures.

Montesano and Singh [4], [44], [45] recently developed a multiscale model for predicting ply crack evolution and stiffness degradation in general symmetric laminates under local multiaxial stress states, based on 3D numerical evaluation of CODs. The model is capable of predicting ply crack evolution in multiple plies simultaneously, while accounting for crack shielding, ply constraining effects (i.e., inter-ply crack interactions), and the influence of 3D Poisson effects on COD and CSD which are notable under multiaxial loading conditions [4]. The model was later implemented into commercial FE software by Montesano et al. [46] in order to simulate progressive failure of large-scale wind turbine blades.

Although the reported models have made significant progress, predicting ply crack evolution and the corresponding laminate stiffness degradation in general multidirectional laminates continues to be a challenge. For instance, accurately predicting the shear modulus degradation of a cracked laminate is a 
limitation for many studies, and mainly due to the challenges in evaluating CSD. In order to determine all the laminate reduced stiffness tensor terms, and to predict crack growth, evaluating both CODs and CSDs for cracks in all corresponding plies is crucial. Furthermore, although the reported studies utilizing 3D meso-mechanical models are able to better capture the physical deformation characteristics of cracked laminates, they are not computationally efficient which limits the robustness of these models. Therefore, the objectives of this study are to develop a comprehensive database for COD and CSD variation for cracks in different plies of general symmetric multidirectional laminates as a function of crack density, multiple ply crack scenario, ply orientation and stacking sequence, ply thicknesses and mechanical properties, and multiaxial stress state. Generalized analytical expressions were developed by fitting this database to inverse sigmoidal functions. Thereafter, these generalized expressions were utilized in conjunction with a damage-based multiscale approach to predict stiffness properties and crack evolution for a variety of multidirectional composite laminates, and were respectively validated with independent FE model predictions and experimental data. Derivation of such unified expressions for COD and CSD have increased the robustness and applicability of our multiscale model, and provided a means to accurately and efficiently predict intra-ply damage growth in general symmetric multidirectional laminates. The developed model may then be coupled with a suitable delamination model and used as a design tool for assessing the long-term durability of composite structures under practical multiaxial stresses. Note that predicting the complex coupled initiation and evolution of intra-ply and delamination cracks in laminates continues to be a limitation for many damage-based models, and is not the focus of this study.

\section{Multiscale model for symmetric laminates with ply cracks}

The developed damage-based model utilized a three-scale approach as illustrated in Fig. 1.

Micromechanics was used to evaluate COD and CSD for cracks in various plies as well as their evolution, while the laminate constitutive equations were developed within a continuum damage mechanics (CDM) framework for evaluating the laminate stiffness. The structural component involved implementation of 
the laminate constitutive equations into commercial FE software for assessing progressive failure of composite structures. The focus of this study is on micromechanics and laminate stiffness evaluation as outlined below, thus the structural component details are omitted (see Ref. [46] for details).

\subsection{Damage-stiffness relationships}

Consider a representative volume element (RVE) for a general symmetric multidirectional laminate with simultaneous cracking in multiple plies resulting from an arbitrary local in-plane multiaxial stress state as shown in Fig. 2. The upper half of the laminate above the symmetry plane is shown, where the arbitrary ply $\alpha$ is characterized by thickness $t_{\alpha}$, orientation $\theta_{\alpha}$, and crack density $\rho_{\alpha}=1 / s_{\alpha}$. Note that the theory is developed to evaluate laminate elastic property degradation for a point in a structure (i.e., the central region of an infinite plate and not a finite specimen), thus possible edge effects, which may influence ply crack initiation and propagation [47], [48], must be excluded. Following continuum damage mechanics concepts, the damage state within the laminate volume can be described through a secondorder tensor [49], where for the damage mode corresponding to cracks in ply $\alpha$ :

$$
D_{i j}^{(\alpha)}=\frac{\kappa_{\alpha} t_{\alpha}^{2}}{s_{\alpha} t} n_{i} n_{j}
$$

Here $n_{i}=\left(\sin \theta_{\alpha}, \cos \theta_{\alpha}, 0\right)$ are components of the unit vector normal to the crack surface, $\kappa_{\alpha}$ is a constraint parameter, and $t$ is the total laminate thickness. The constraint parameters represent the ply constraining effect from the adjacent plies, and are quantified using the crack surface displacements [4]. The corresponding stiffness tensor for a thin symmetric orthotropic laminate containing cracks is obtained via the Helmholtz free energy, $\psi\left(\varepsilon_{i j}, D_{i j}^{(\alpha)}\right)$, and is defined by:

$$
C_{i j k l}=\frac{\partial^{2} \psi}{\partial \varepsilon_{i j} \partial \varepsilon_{k l}}=\left[\begin{array}{ccc}
\frac{E_{x}^{o}}{1-v_{x y}^{o} v_{y x}^{o}} & \frac{v_{x y}^{o} E_{y}^{o}}{1-v_{x y}^{o} v_{y x}^{o}} & 0 \\
\frac{v_{x y}^{o} E_{y}^{o}}{1-v_{x y}^{o} v_{y x}^{o}} & \frac{E_{y}^{o}}{1-v_{x y}^{o} v_{y x}^{o}} & 0 \\
0 & 0 & G_{x y}^{o}
\end{array}\right]-\sum_{\alpha} a_{\alpha} D_{\alpha}\left[\begin{array}{ccc}
2 a_{1}{ }^{(\alpha)} & a_{4}{ }^{(\alpha)} & 0 \\
a_{4}{ }^{(\alpha)} & 2 a_{2}{ }^{(\alpha)} & 0 \\
0 & 0 & 2 a_{3}^{(\alpha)}
\end{array}\right]
$$


The first term on the right hand side of Eq. (2) contains the undamaged orthotropic laminate engineering constants evaluated using CLT, and the second term represents laminate stiffness changes brought about by summing the effects of damage in different plies. Here $a_{i}^{(\alpha)}$ are the corresponding orthotropic damage constants which govern degradation of the laminate properties, mainly $E_{x}^{o}, E_{y}^{o}, G_{x y}^{o}, v_{x y}^{o}, v_{y x}^{o}$, and are functions of the ply orientation. The $D_{\alpha}$ terms are the effective damage parameters, and include the constraint parameters defined in Eq. (1). The orthotropic damage constant matrix assumes that a damaged laminate remains symmetric (i.e., a ply below the symmetry plane has the same crack density as the corresponding ply above the symmetry plane). Equation (2) represents a direct link between the damaged laminate stiffness matrix and the microscopic damage state. For a given damage state, the stresses $\sigma_{i j}$ and strains $\varepsilon_{k l}$ are related through the following damage-dependent linear elastic constitutive law

$$
\sigma_{i j}=C_{i j k l}\left(D_{i j}^{(\alpha)}\left(\rho_{\alpha}\right)\right) \varepsilon_{k l}
$$

It should be noted that curing and temperature effects have not been considered in this study, thus corresponding strains induced by thermal expansion and residual strains due to curing are not included in Equation (3). Thermal strains and residual strains would alter the local ply stresses and as a result potentially influence the ply CODs and CSDs discussed in the subsequent section.

The stiffness tensor defined by Eq. (2) is representative for a symmetric laminate containing an arbitrary distribution of ply cracks in multiple plies. In order to describe the evolution of ply cracks under an applied loading condition, an energy-based approach based on fracture mechanics concepts requiring averaged COD and CSD values was invoked. The details are omitted here for brevity, however, can be found in Ref. [44].

\subsection{Micro damage mechanics}

The damage tensor and crack evolution scheme described in the previous section require evaluation of the ply-specific averaged crack surface displacements. The required averaged CODs and CSDs for an arbitrary ply $\alpha$ are defined by: 


$$
\begin{aligned}
& \left(\overline{\Delta u_{2}}\right)_{(\alpha)}=\frac{1}{t_{\alpha}} \int_{-t_{\alpha} / 2}^{t_{\alpha} / 2} \Delta u_{2}^{\alpha}(z) d z \\
& \left(\overline{\Delta u_{1}}\right)_{(\alpha)}=\frac{1}{t_{\alpha}} \int_{-t_{\alpha} / 2}^{t_{\alpha} / 2} \Delta u_{1}^{\alpha}(z) d z
\end{aligned}
$$

Here, $\Delta u_{2}^{\alpha}(z)$ and $\Delta u_{1}^{\alpha}(z)$ represent local relative crack surface displacements in the normal (i.e., opening) and fiber (i.e., sliding) directions, respectively, and are functions of the position through the ply thickness. These parameters can be evaluated through shear-lag type [20] or variational models [23], however, improved accuracy and a wider range of applicability can be obtained through FE analysis.

In previous work, 3D meso-mechanical FE models were developed for this purpose, where numerically Eqs. (4) and (5) are applied to the nodes on the corresponding crack surfaces [4]. An example analysis for a $[0 / 90 / \mp 45]_{\mathrm{s}}$ glass/epoxy laminate containing cracks in multiple plies while subjected to imposed equibiaxial strains of $0.5 \%$ in both the $x$ - and $y$-directions using the commercial software ANSYS is shown in Fig. 3. Three-dimensional continuum elements (SOLID 186) were used to mesh the half laminate volume, and each ply was modeled as a homogeneous linear elastic transversely isotropic material with $E_{2}=E_{3}, G_{12}=G_{13}, v_{12}=v_{13}$ and $G_{23}=0.5 E_{2} /\left(1+v_{23}\right)$. The crack spacing was assumed to be uniform within a ply, and cracks spanned the width of the RVE and the ply thickness. Periodic boundary conditions were also applied to the model [4], which allowed for variation in the applied in-plane multiaxial stress state, simultaneous cracking in multiple plies (i.e., inter-ply crack interactions), variable ply crack densities, and capturing of the local in-plane shear effects and shear modulus degradation. Constant displacements were applied to the faces of the RVE in order to represent in-plane strains, where magnitudes ranging from $0.25 \%$ to $1.0 \%$ were used depending on the desired multiaxial loading ratio. In the present study, a wide range of material properties, ply thickness and stacking sequences were investigated for the analysis, where similar meso-mechanical FE models were invoked. The laminates studied are identified and listed in Table 1, along with the corresponding ply properties and constant ply thicknesses. Although FE analysis of crack surface displacements provides a wider range of applicability, generating a database for many laminates can be computationally expensive. Therefore, a set of general 
analytical expressions were developed for both COD and CSD for arbitrary plies in general multidirectional symmetric laminates as is described in the subsequent section, and comparisons were made with the meso-mechanical FE results from which the analytical expressions were fitted. The general COD and CSD expressions were then utilized to evaluate stiffness degradation and ply crack evolution for a number of symmetric laminates.

\section{Analysis of COD and CSD}

A key goal of this study was to develop general expressions for COD and CSD, thus the first step was to normalize these terms. Since linear elastic deformation is assumed, it can be shown that the averaged crack opening and sliding displacements, $\left(\overline{\Delta u_{2}}\right)_{(\alpha)}$ and $\left(\overline{\Delta u_{1}}\right)_{(\alpha)}$, are proportional to the ply strain (or stress) state as well as the ply thickness, $t_{\alpha}[4]$. Thus, for an arbitrary ply $\alpha$ in a symmetric laminate, the load- and thickness-independent normalized CODs and CSDs are defined by:

$$
\begin{aligned}
& \left(\overline{\Delta u_{2 n}}\right)_{(\alpha)}=\frac{\left(\overline{\Delta u_{2}}\right)_{(\alpha)}}{\varepsilon_{e f f} t_{\alpha}} \\
& \left(\overline{\Delta u_{1 n}}\right)_{(\alpha)}=\frac{\left(\overline{\Delta u_{1}}\right)_{(\alpha)}}{\left|\gamma_{12}\right| t_{\alpha}}
\end{aligned}
$$

where the effective ply strain, $\varepsilon_{\text {eff }}=\varepsilon_{22}+v_{12} \varepsilon_{11}+\frac{1}{8} v_{21} \gamma_{12}$. The cracked ply strain components $\varepsilon_{22}, \varepsilon_{11}$ and $\gamma_{12}$ respectively represent the far field strains (from CLT, resulting from the applied macroscopic loads on the laminate) transformed along the ply transverse, fiber and in-plane shear directions, while $v_{12}$ and $v_{21}$ are the ply in-plane major and minor Poisson's ratios. An effective ply strain was used in the normalization of the averaged CODs in order to account for 3D Poisson effects at the ply level, which can notably influence the magnitude of CODs when plies are subjected to multiaxial strain states as was described in Ref. [4]. In order to provide a physical basis, consider that a ply under in-plane axial and shear strains, $\varepsilon_{11}$ and $\gamma_{12}$, will also exhibit through-thickness strains $\left(\varepsilon_{33}\right)$ due to Poisson effects, which 
have been shown to increase the magnitude of CODs [44]. Since the CLT expressions do not contain $\varepsilon_{33}$, the in-plane strains were chosen in the effective ply strain term to represent this $3 \mathrm{D}$ effect. It is important to note that normalizing the averaged crack displacements with $\varepsilon_{\text {eff }}$ and $\gamma_{12}$ ensures that the data is more conducive for implementation into displacement-based FE software.

The next step involved assessing the variation of normalized CODs and CSDs with increasing crack density in a specific ply under an arbitrary stress state. From the physical situation, as the ply crack density increases (i.e., the crack spacing, $s_{\alpha}$, decreases) the stress contours between cracks eventually begin to overlap, causing a reduction in the stress magnitude near the crack surfaces and a corresponding reduction in the crack surface displacements (i.e., the so-called crack shielding effect). This effect is shown in Fig. 4 where normalized CODs and CSDs for different plies of a $[0 / 90 / \mp 45]_{s}$ laminate are plotted with respect to crack density. The normalized crack surface displacements were evaluated using Eqs. (6) and (7) along with data from meso-mechanical FE models (described in Section 2), and are representative for arbitrary applied loads due to the normalized COD and CSD expressions. Results for the same laminate with carbon/epoxy and glass/epoxy material properties are shown in Fig. 4, which clearly demonstrate that the normalized crack surface displacements decrease nonlinearly with increasing crack density, as reported in previous studies [4], [12]. It must be highlighted that the relationship between the normalized crack surface displacements and crack density is distinct for each ply in a laminate, and is due in part to the ply constraining effect which can be correctly captured through the 3D FE analysis. In general, variations of normalized COD and CSD depend on laminate stacking sequence, as well as the ply properties and thickness. Particularly in Fig. 4, it is clear that the glass/epoxy and carbon/epoxy results are comparable for a particular ply which is due to the fact that the same ply thickness was used to normalize the crack surface displacements. Slight variations are a result of the corresponding ply constraining effects which will alter the normalized CODs and CSDs since all laminate plies have the same thickness. Also, there is a larger variation in $\left(\overline{\Delta u_{2}}\right)_{(\alpha)}$ and $\left(\overline{\Delta u_{1}}\right)_{(\alpha)}$ with crack 
density for the external $0^{\circ}$ ply as shown in Fig. 4 since they are only constrained on one side, and therefore exhibit a higher dependence on crack density.

Capturing the crack shielding effect is critical for accurately predicting crack evolution and assessing the corresponding laminate stiffness (see Eq. (3)). In recent work by the authors, a single continuous inverse sigmoidal function was found to accurately represent the variation of normalized CODs at low, intermediate and high crack densities [4]. Therefore, the inverse sigmoidal functions defined by Eqs. (8) and (9) were used in this study to develop general analytical expressions for both $\left(\overline{\Delta u_{2 n}}\right)_{(\alpha)}$ and $\left(\overline{\Delta u_{1 n}}\right)_{(\alpha)}$ in terms of ply crack density, $\rho_{\alpha}$, for any ply $\alpha$ in arbitrary symmetric multidirectional laminates under a wide range of practical crack densities.

$$
\begin{aligned}
& \left(\overline{\Delta u_{2 n}}\right)_{(\alpha)}=\frac{A_{2}}{1+\left(D_{2} \rho_{\alpha}\right)^{F_{2}}} \\
& \left(\overline{\Delta u_{1 n}}\right)_{(\alpha)}=\frac{A_{1}}{1+\left(D_{1} \rho_{\alpha}\right)^{F_{1}}}
\end{aligned}
$$

It should be made clear that the expressions in Eqs. (8) and (9) were the result of fitting normalized crack surface displacement versus crack density data (evaluated using Eqs. (6) and (7) with data generated from meso-mechanical FE models containing cracks, such as that shown in Fig. 4) for various plies in different laminates. The mode specific ply constraining coefficients $A, D$ and $F$ are functions of the cracked and adjacent ply thicknesses and properties, as well as the orientation of the adjacent plies, and will be described in the subsequent paragraph. In addition, the ply constraining coefficients are distinct for external plies located on the surface of the laminate compared to those located internally. This is due to the fact that internal plies are constrained on both surfaces (e.g., see $90^{\circ}$ or $-45^{\circ}$ plies in Fig. 3), while external plies are constrained on one surface only (e.g., see $0^{\circ}$ ply in Fig. 3). This leads to distinct crack surface displacement profiles, which results in a different set of ply constraining coefficients as will be described in the subsequent paragraph. The importance of Eqs. (8) and (9) is that for a specific ply in an arbitrary laminate with crack density $\rho_{\alpha}$ under a general multiaxial stress state, the normalized CODs or 
CSDs can be directly evaluated and used to predict ply crack evolution as well as laminate stiffness degradation.

The next step involved evaluating general expressions for the mode specific ply constraining coefficients by considering their relation to the ply properties, ply thicknesses and laminate stacking sequence, and was accomplished by fitting numerical data for multiple laminates. Considering first the normalized CODs (i.e., mode I), the ply constraining coefficients for both internal and external plies can be evaluated from the following expressions:

$$
\begin{gathered}
A_{2}^{\text {(int) }}=1.15+\left(\frac{1}{E_{C R}}\right)\left[\left(\frac{1}{t_{\text {eff }}}\right)^{\frac{E_{2}}{E_{1}}}\right], F_{2}^{\text {(int) }}=1.50+\left(\frac{1}{E_{C R}}\right)\left[\left(\frac{1}{t_{\text {eff }}}\right)^{\left.\frac{E_{2}}{E_{1}}\right], D_{2}^{(\text {int })}=0.70 t_{\alpha}}\right. \\
A_{2}^{\text {(ext) }}=3.10+0.30\left(\frac{1}{E_{C R}}\right)\left[\left(\frac{1}{t_{\text {eff }}}\right)^{\frac{E_{2}}{E_{1}}}\right], F_{2}^{(\mathrm{ext})}=1.50+\left(\frac{1}{E_{C R}}\right)\left[\left(\frac{1}{t_{\text {eff }}}\right)^{\frac{E_{2}}{E_{1}}}\right], D_{2}^{\text {(ext) }}=1.90 t_{\alpha}
\end{gathered}
$$

The terms $E_{C R}$ and $t_{\text {eff }}$ are respectively non-dimensional ratios with regards to ply modulus and thickness, and are defined by

$$
\begin{gathered}
E_{C R}=\frac{E_{2, \alpha-1}^{\prime}+E_{2, \alpha}+E_{2, \alpha+1}^{\prime}}{E_{2, \alpha}} \\
t_{\text {eff }}=\frac{t_{\alpha-1}+t_{\alpha}+t_{\alpha+1}}{t_{\alpha}}
\end{gathered}
$$

The ratio $E_{C R}$ represents the constraining effects from the adjacent plies on the COD of ply $\alpha$. Here, $E_{2, \alpha}$ is the modulus of the cracked ply (i.e., ply transverse modulus, $E_{2}$ ). $E_{2, \alpha-1}^{\prime}$ and $E_{2, \alpha+1}^{\prime}$ are the transformed moduli of the adjacent plies in the direction normal to the cracked ply fibers - these can be altered as a result of cracking in the adjacent plies. It should be noted that for the laminates considered in the present study, considering only the plies immediately adjacent to the cracked ply (i.e., plies $\alpha-1$ and $\alpha+1$ ) was deemed suitable. If the constraining effects of additional plies are required (i.e., ply $\alpha-2, \alpha+2$, etc.), then the transformed moduli can be evaluated to account for the contribution of these plies using CLT. The ratio, $t_{\text {eff }}$, is a function of the cracked ply thickness, $t_{\alpha}$, and the thickness of the adjacent plies, $t_{\alpha-1}$ and $t_{\alpha+1}$ 
(see Fig. 3). The numerical coefficients in Eqs. (10) and (11) are constants which have resulted from fitting the inverse sigmoidal expressions for various ply properties, thicknesses and stacking sequences. The significance of the expressions in Eqs. (10) and (11) is that they effectively facilitate the generalization of the expression for normalized CODs (Eq. (8)) for any ply in an arbitrary laminate.

Similarly for normalized CSDs, general expressions for the ply constraining coefficients for internal and external plies are defined by the following expressions:

$$
\begin{aligned}
& A_{1}^{(\mathrm{int})}=0.44+0.20\left[\left(\frac{1}{G_{C R}}\right)^{-\frac{1}{t_{\text {eff }}}}\right], F_{1}^{(\mathrm{int})}=2.00-0.35\left[\left(\frac{1}{G_{C R}}\right)^{-\frac{1}{t_{\text {eff }}}}\right], D_{1}^{(\mathrm{int})}=0.55 t_{\alpha} \\
& A_{1}^{(\mathrm{ext})}=2.30-0.50\left[\left(\frac{1}{G_{C R}}\right)^{-\frac{1}{t_{e f f}}}\right], F_{1}^{(\mathrm{ext})}=2.00-0.35\left[\left(\frac{1}{G_{C R}}\right)^{-\frac{1}{t_{e f f}}}\right], D_{1}^{(\mathrm{ext})}=1.10 t_{\alpha}
\end{aligned}
$$

Analogous to $E_{C R}$, the ratio $G_{C R}$ represents the constraining effect from the adjacent plies on CSD of ply $\alpha$, and is defined by:

$$
G_{C R}=\frac{G_{12, \alpha-1}^{\prime}+G_{12, \alpha}+G_{12, \alpha+1}^{\prime}}{G_{12, \alpha}}
$$

The term $G_{12, \alpha}$ is the cracked ply shear modulus, while $G_{12, \alpha-1}^{\prime}$ and $G_{12, \alpha+1}^{\prime}$ represent the transformed shear moduli of the adjacent plies in the 1-2 direction of the cracked ply, $\alpha$. It should be noted that for external plies, $E_{2, \alpha-1}^{\prime}=0, G_{12, \alpha-1}^{\prime}=0$ and $t_{\alpha-1}=0$ for the analysis presented in this study.

The generalized model defined by Eqs. (6) - (16) can be used to predict CODs and CSDs for any ply in any symmetric laminate subjected to in-plane multiaxial stresses, with simultaneous ply cracking. A key advantage of this model is that its formulation does not change for different types of laminates (i.e., cross-ply, angle-ply, multidirectional), and thus it is easily implemented into commercial FE software. Note that for the laminates studied here, the crack density in only ply $\alpha$ was considered when evaluating normalized crack surface displacements since cracking in the adjacent plies (i.e., plies $\alpha-1$ and $\alpha+1$ ) had a negligible influence. For example, consider a plot of the normalized CSD versus crack density for the $0^{\circ}$ 
ply of a $[0 / 90 / \mp 45]_{\mathrm{s}}$ laminate (L01) under an arbitrary multiaxial stress state as shown in Fig. 5a; the profile of the data follows an inverse sigmoidal function when there are no cracks in the adjacent $90^{\circ}$ ply. As the crack density in the $90^{\circ}$ ply increases, the variation in $0^{\circ}$ ply CSD profile is negligible (i.e., $<5 \%$ at high $\rho_{90}$ and $<1 \%$ at low $\rho_{90}$ ), which suggests that the effects of crack density in the adjacent plies can be neglected. Also, it should be reiterated that the normalized COD and CSD data presented in this section are representative for a ply in a laminate under a range of multiaxial stress states and stress magnitudes (i.e., independent of the applied load), which is due to the normalization used in Eqs. (6) and (7). Figure $5 \mathrm{~b}$ demonstrates that for the $0^{\circ}$ ply in laminate L01 the normalized COD profiles are identical for three distinct load cases of arbitrary magnitude, mainly uniaxial, equibiaxial and combined uniaxial/shear - the averaged COD values were distinct. Similar trends as shown in Fig. 5 were found for all laminates investigated in this work, and are not presented for brevity.

In order to demonstrate the accuracy and applicability of the generalized model, normalized crack surface displacements evaluated using Eqs. (8) - (16) are plotted with the corresponding data from the meso-mechanical FE analysis of crack-containing laminates that were used to fit the model. These plots are found in Figs. 6-8, and are representative for arbitrary applied loads due to the normalized COD and CSD expressions. In Fig. 6a, the normalized CODs for $90^{\circ}$ plies in the cross-ply laminates L05 - L07 evaluated using the fitted model and from FE analysis are plotted. Similar plots are shown in Fig. $6 \mathrm{~b}$ for normalized CSDs of the same $90^{\circ}$ plies. In all cases, the fitted model data goodness of fit values $\left(\mathrm{R}^{2}\right)$ were $>0.95$, which demonstrates the accuracy of the generalized expressions with respect to the FE results. It is clear that the model accuracy is excellent at intermediate and high crack densities, for both $\left(\overline{\Delta u_{2 n}}\right)_{(\alpha)}$ and $\left(\overline{\Delta u_{1 n}}\right)_{(\alpha)}$. There is slight deviation at lower crack densities, however, this did not impact the stiffness calculations and thus was deemed suitable. Note that the distinct normalized COD/CSD profiles for the $90^{\circ}$ plies of laminates L05 and L07 shown in Fig. 6 result from the variation in the thickness of the corresponding plies. Although the crack surface displacements are normalized with ply thickness, the 
thickness of the constraining $0^{\circ}$ plies is also distinct for L05 and L07 which has altered their influence on the cracked $90^{\circ}$ plies and thus changed the normalized COD/CSD profiles. The versatility of the analytical model to consider different ply thicknesses and different ply materials (e.g., GFRP and CFRP) is clearly illustrated. Figure 7 shows normalized CODs and CSDs for the internal and external plies of laminate L09, which were evaluated using the fitted model and the FE data. Again, the fitted model correlates well with the FE data $\left(\mathrm{R}^{2}>0.95\right)$, further illustrating the applicability of the analytical expressions for arbitrary symmetric laminates under general in-plane multiaxial stresses. Additional $\left(\overline{\Delta u_{2 n}}\right)_{(\alpha)}$ and $\left(\overline{\Delta u_{1 n}}\right)_{(\alpha)}$ data is plotted in Fig. 8 for the quasi-isotropic laminates L01, L03 and L04, once again demonstrating the excellent correlation between the fitted model and FE data. The analytical model is capable of capturing variations in COD and CSD for different plies in each quasi-isotropic laminate, regardless of the specific stacking sequence or ply material.

\section{Prediction of stiffness degradation and damage evolution}

The ultimate goal of damage-based models is to predict crack evolution and the corresponding laminate stiffness corresponding to each particular damage state in order to facilitate material degradation during progressive failure analysis. First, the elastic constants for various laminates corresponding to different crack densities and scenarios were evaluated using the analytical expressions for COD and CSD (Eqs. (8) and (9)) along with the damage-stiffness relations (Eq. (2)), which will hereafter be referred to as the model. As a form of validation, the elastic constants were also assessed directly from the 3D mesomechanical FE analysis models through volume averaged stresses and strains of the RVEs (see Ref. [4] for details). The comparisons are found in Sections 4.1 and 4.2, where the crack densities corresponding to various crack states were assumed (i.e., ply crack evolution was not predicted in these Sections). Approximations using the ply discount method are also presented in this section, and represent a limit for the degradation of the laminate elastic constants at higher crack densities. Subsequently, ply crack evolution for the laminates studied was predicted and compared with available experimental data from the 
literature. Due to the limited ply crack evolution data available for laminates under multiaxial loads, the predictions presented in Section 4.3 are limited to laminates subjected to uniaxial loads.

\subsection{Uniaxial stress state - cracks in $90^{\circ}$ plies}

The normalized elastic constants for the $[0 / 90]_{\mathrm{S}}$ GFRP, $\left[0 / 90_{2}\right]_{\mathrm{S}}$ GFRP and $[0 / 90]_{\mathrm{S}}$ CFRP laminates (i.e., L05, L06, L07 from Table 1) containing cracks in the internal $90^{\circ}$ plies were evaluated at various crack densities. The corresponding normalized axial modulus, $E_{x} / E_{x}{ }^{o}$, Poisson ratio, $v_{x y} / v_{x y}{ }^{o}$, and in-plane shear modulus, $G_{x y} / G_{x y}{ }^{o}$, are shown in Fig. 9. The model predictions correlate very well with the FE data for the cross-ply laminates at low, intermediate and high crack densities, and approach the ply discount limit at much higher crack densities as was expected. The robustness of the model is clear from Fig. 9 since accuracy remains high with variations in the ply thickness and ply material properties. It is intuitive that for a given crack density laminates with thicker plies tend to cause greater stiffness degradation due to increased crack surface area (see Fig. 9). Also, laminates with thicker plies tend to exhibit steeper degradation at lower crack densities prior to a gradual degradation at higher crack densities [22], [50]; this is also evident when comparing the plots in Fig. 9. For example, a $90^{\circ}$ ply crack density of $0.5 \mathrm{~mm}^{-1}$ degrades the axial modulus $\left(E_{x}\right)$ of laminate L05 and L06 by $12 \%$ and $28 \%$, respectively. Increasing the thickness of the $90^{\circ}$ ply by a factor of 2 more than doubles $E_{x}$ degradation. For laminate L07, the degradation of $E_{x}$ is a mere $1 \%$ at $0.5 \mathrm{~mm}^{-1}$, illustrating the effect of much thinner plies and added constraining effect due to the much stiffer CFRP ply properties. Furthermore, the magnitude of percent degradation of $v_{x y}$ is greater than $E_{x}$, and consistent with experimental findings of similar cross-ply laminates [2], [50]. For example, at a crack density of $2 \mathrm{~mm}^{-1}$ laminate L05 exhibited a degradation for $v_{x y}$ and $E_{x}$ of $45 \%$ and $19 \%$, respectively. It should be noted that since there were only $90^{\circ}$ ply cracks for all laminates considered in Fig. 9, the degradation of $E_{y}$ was negligible. It is also important to note that the presented model is capable of predicting degradation of the laminate in-plane shear modulus, in addition to the axial modulus, transverse modulus and in-plane Poisson ratio. This is attributed to the use of the $a_{3}$ term in the degradation matrix of Eq. (2), and accounting for 3D deformation of the damaged laminates 
[4]. This is seen as a major advantage since many previous models presented in the literature are unable to predict the degradation of $G_{x y}$, which is critical for assessment of practical structures under multiaxial stresses where shear deformation may be prevalent.

Similar plots of $E_{x} / E_{x}{ }^{o}, v_{x y} / v_{x y}{ }^{o}$, and $G_{x y} / G_{x y}{ }^{o}$ as functions of crack density for quasi-isotropic GFRP and CFRP laminates (i.e., L01, L02, L03 from Table 1) with cracks only in the internal $90^{\circ}$ plies are shown in Fig. 10. Again, the model predictions for all in-plane properties correlate very well with the FE data at low, intermediate and high crack densities for laminates with different ply thicknesses and properties. It should be noted that some of the plots in Fig. 10 did not yet approach the ply discount limit at a crack density of $2 \mathrm{~mm}^{-1}$ (e.g., laminate L02). For these laminates, this would require much higher crack densities, and since these crack densities are not practically achievable they were not considered in this study. Degradation of Poisson's ratio and axial modulus are comparable for these quasi-isotropic laminates at approximately $10 \%, 7 \%$ and $3 \%$ respectively for laminate L01, L02 and L03, and consistent with experimental data for similar laminates [2]. By comparing the plots in Figs. 9 and 10, it is clear that degradation of the quasi-isotropic laminates are less severe when compared to the cross-ply laminates studied here. This is mainly a result of lower effective ply thicknesses for the quasi-isotropic laminates and additional constraining effects caused by the $\pm 45^{\circ}$ plies.

\subsection{Multiaxial stress state - simultaneous cracks in multiple plies}

In order to investigate the model accuracy for laminates with simultaneous cracking in multiple plies, and thus representing crack states exhibited under multiaxial stresses, the $[0 / 90]_{\mathrm{s}}(\mathrm{L} 05),[0 / 90 / \mp 45]_{\mathrm{s}}$ (L01), and $[ \pm 45]_{\mathrm{s}}$ (L09) GFRP laminates were considered. Plots of $E_{x} / E_{x}{ }^{o}, E_{y} / E_{y}{ }^{o}, v_{x y} / v_{x y}{ }^{o}$, and $G_{x y} / G_{x y}{ }^{o}$ as functions of crack density for cross-ply laminate L05 with the same crack density in both internal $90^{\circ}$ and external $0^{\circ}$ plies are shown in Fig. 11. The model correlates very well with the FE data at all crack densities, with the exception of the in-plane shear modulus at higher crack densities which is under predicted. This discrepancy likely results from the fact that ply cracking in the adjacent plies was not considered in this study when evaluating $G_{12, \alpha-1}^{\prime}$ and $G_{12, \alpha+1}^{\prime}$ (see Eq. (16)). Ply cracking in a ply adjacent 
to ply $\alpha$ will reduce the ply constraining effect at higher crack densities and cause an increase in crack surface displacements in ply $\alpha$, which will then cause increased laminate stiffness degradation. This is clearly captured by the FE analysis and not by the analytical model. Note, however, that if suitable expressions for effective modulus of cracked adjacent plies are used to evaluate $G_{12, \alpha-1}^{\prime}$ and $G_{12, \alpha+1}^{\prime}$ (for example see Ref. [40]), the accuracy of these simulations will improve. Comparisons of the plots in Figs. 9 and 11 for laminate L05 indicate that axial stiffness degradation is virtually the same since $0^{\circ}$ ply cracks have negligible influence. The transverse and axial stiffness degradation shown in Fig. 11 are also comparable with magnitudes of $20 \%$ when the crack density in each ply is $2 \mathrm{~mm}^{-1}$, and is a result of the thicker central $90^{\circ}$ ply and the external $0^{\circ}$ ply having the same influence on the laminate $E_{x}$ and $E_{y}$, respectively. Also, the addition of $0^{\circ}$ ply cracks has increased the laminate shear modulus and Poisson ratio degradation respectively by an additional $40 \%$ and $45 \%$ (see Figs. 9 and 11), and results from its reduced resistance to transverse and shear deformation.

Plots illustrating degradation of $E_{x} / E_{x}{ }^{o}, E_{y} / E_{y}{ }^{o}, v_{x y} / v_{x y}{ }^{o}$, and $G_{x y} / G_{x y}{ }^{o}$ for laminate L01 with the indicated crack density profiles in $90^{\circ},+45^{\circ}$ and $-45^{\circ}$ plies are shown in Fig. 12 . The model predictions for all in-plane properties correlate very well with the FE data, where the discontinuity in the degradation plots caused by initiation of $\pm 45^{\circ}$ ply cracks at a $90^{\circ}$ ply crack density of $0.75 \mathrm{~mm}^{-1}$ is accurately captured. Note that it was assumed the $\pm 45^{\circ}$ ply cracks initiated when cracking in the $90^{\circ}$ plies was 0.75 $\mathrm{mm}^{-1}$ (i.e., the evolution of cracks was not predicted). Comparison of Figs. 10 and 12 reveal that the axial modulus degradation increased by $11 \%$ due to the additional $\pm 45^{\circ}$ ply cracks, while degradation of $v_{x y}$ and $G_{x y}$ increased respectively by $1 \%$ and $6 \%$. Also, degradation due of the transverse modulus was approximately $10 \%$ at a $\pm 45^{\circ}$ ply crack density of $0.8 \mathrm{~mm}^{-1}$. Similar plots for angle-ply laminate $\mathrm{L} 09$ for the indicated crack densities in $\pm 45^{\circ}$ plies are shown in Fig. 13. It should be noted that for this laminate the model is able to capture the uncharacteristic increase of the in-plane Poisson ratio at increasing crack densities. This behaviour has been reported previously by the authors for a similar angle-ply laminate [4], 
and is supported by experimental evidence in the study by Varna [51] for a $[0 / \pm 45 / 0]_{\mathrm{s}}$ laminate containing cracks in the $\pm 45^{\circ}$ plies.

\subsection{Ply crack evolution}

The final goal of this study was to utilize the generalized analytical expressions for COD and CSD developed in Section 3 in conjunction with the energy-based ply crack evolution scheme detailed in Ref. [44] to predict the initiation and evolution of ply cracks for symmetric laminates. Here, the predictions were limited to laminates L01, L05, L07 and L08 since corresponding experimental crack density data was available in the literature. The $90^{\circ}$ ply crack density evolution for the CFRP cross-ply laminates (L07 and L08) subjected to quasi-static tensile loading are shown in Fig. 14, which includes the model predictions and experimental data from Ref. [17]. The predicted crack density evolution correlates very well with the experimental data for the two CFRP cross-ply laminates. The ability to predict lower $90^{\circ}$ ply crack initiation stress for the laminate containing a thicker transverse layer was demonstrated, and is consistent with findings in previous studies [24], [35]. This result is attributed to the energy-based approach used in this study as well as the accuracy of the normalized COD/CSD terms evaluated using Eqs. (8) and (9). The saturation of $90^{\circ}$ ply cracks was not predicted for laminates L07 and L08, which is consistent with the experimental observations [17] as illustrated in Fig. 14 by a continuously increasing crack density.

Figure 15 shows predicted and experimental ply crack density evolution for $[0 / 90]_{\mathrm{s}}$ and $[0 / 90 / \mp 45]_{\mathrm{s}}$ GFRP laminates (L05 and L01) subjected to quasi-static uniaxial tensile loads. For both laminates, the predicted $90^{\circ}$ ply crack initiation load and subsequent crack density evolution correlates well with the available experimental data from Ref. [2]. For both laminate L05 and L01 the model accurately predicted the observed crack saturation of $90^{\circ}$ ply cracks at higher density, which is indicated by the decreasing slope of the predicted curves in Fig. 15, demonstrating the ability of the model to accurately predict the so-called crack shielding effect. In Ref. [2] the crack density for the off-axis plies of the $[0 / 90 / \mp 45]_{\mathrm{s}}$ GFRP laminate was not reported, where instead crack initiations strains for the $-45^{\circ}$ and $+45^{\circ}$ plies were 
reported as $1.0 \%$ and $1.15 \%$, respectively. These values correspond well with those predicted for the offaxis plies by the model as shown in Fig. $15 \mathrm{~b}$.

\subsection{General discussion}

For the symmetric laminates studied, the predicted laminate elastic property variation with crack density compared well with data obtained from the independent FE simulations of crack containing laminates. Furthermore, predictions of crack density evolution for the L01, L05, L07 and L08 laminates correlated well with available experimental data from the literature. Nonetheless, in order to apply the model to additional laminates a few model limitations must be addressed in future work. First, in the present study the effects of adjacent ply crack density on ply constraining were not considered when evaluating the effective adjacent ply moduli. Since this simplification may cause slightly under predicted stiffness degradation at higher crack densities for other laminates, corresponding expressions for degraded lamina moduli should be integrated into the model. It should also be noted that accounting for additional adjacent plies when evaluating the effective adjacent ply moduli may also be required for other laminates not considered in this study, and may further mitigate these slight discrepancies. Also, lamina nonlinear shear deformation was not considered in the present study. Although not critical for the laminates studied here, the impact of shear nonlinearity must be assessed for other laminates with larger off-axis angles. In addition, in practical applications a symmetric laminate subjected to an arbitrary applied loading condition may not necessarily undergo a damage process that is distributed symmetrically among the plies. Therefore, the applicability of the model may be extended by incorporating a non-symmetric damage tensor to account for non-symmetric damage process.

\section{Conclusions}

A comprehensive study was conducted in order to analyze ply crack surface opening (COD) and sliding displacements (CSD) for different plies in general symmetric multidirectional laminates subjected to arbitrary in-plane multiaxial stress states. General unified analytical expressions were derived for 
evaluating CODs and CSDs at various crack densities, including at higher crack densities where intra-ply crack interactions (i.e., crack shielding) become significant. These expressions were first used to evaluate the dependence of elastic properties on crack density for various symmetric laminates using an analytical multiscale model developed by the authors, and validation was accomplished using data generated from independent 3D meso-mechanical finite element analysis of cracked laminate representative volume elements. The axial and transverse modulus, in-plane Poisson ratio and shear modulus degradation for various cross-ply laminates with cracks in individual plies and simultaneously in multiple plies correlated well with finite element data. Similar results for various quasi-isotropic and angle-ply laminates also demonstrated the accuracy of the model at various crack densities, where variation in laminate elastic constant degradation for different ply thickness and material properties was well captured. Next, the general expressions for COD and CSD were used with an energy-based approach to evaluate crack density evolution for laminates under quasi-static tensile loads. The predicted crack density profiles correlated very well with available experimental data.

The developed unified expressions can be used to evaluate both CODs and CSDs for any ply in a general symmetric multidirectional laminate under arbitrary in-plane multiaxial stress states and crack densities, which is a major contribution of this study. This is important for increasing the robustness and range of applicability of the damage-based multiscale model, and the simple expressions coupled with the laminate constitutive equations allow for ease of model implementation into commercial finite element software for structural analysis. In addition, the model was able to account for shear modulus degradation, simultaneous ply cracking in multiple plies, both intra-ply and inter-ply crack interactions, and the 3D nature of ply constraining effects, which is advantageous when compared to other models reported in the literature. With these advancements the model can be invoked to efficiently predict ply crack multiplication in laminates under combined stress states, and when coupled with a suitable delamination model may be used as a design tool to predict progressive failure of critical load-bearing structures to assess their long-term durability. 


\section{Acknowledgements}

The authors acknowledge financial support from the Natural Sciences and Engineering Research Council of Canada (NSERC) through the Discovery and Automotive Partnership Canada grants, the University of Waterloo, and the University of Toronto.

\section{References}

[1] Talreja R. Transverse cracking and stiffness reduction in composite laminates. J Compos Mater 19;1985:355-375.

[2] Tong J, Guild FJ, Ogin SL, Smith PA. On matrix crack growth in quasi-isotropic laminates - I. experimental investigation. Compos Sci Technol 1997;57:1527-1535.

[3] Tong J, Guild FJ, Ogin SL, Smith PA. On matrix crack growth in quasi-isotropic laminates - II. finite element analysis. Compos Sci Technol 1997;57:1537-1545.

[4] Montesano J, Singh CV. A synergistic damage mechanics based multiscale model for composite laminates subjected to multiaxial strains. Mech Mater 2015;83:72-89.

[5] Chen JF, Morozov EV, Shankar K. Simulating progressive failure of composite laminates including in-ply and delamination damage effects. Compos Part A 2014;61:185-200.

[6] Hoiseth K, Qu J. Cracking paths at the ply interface in a cross-ply laminate. Compos Part B 2003;34:437-445.

[7] Farrokhabadi A, Hosseini-Toudeshky H, Mohammadi B. A generalized micromechanical approach for the analysis of transverse crack and induced delamination in composite laminates. Compos Struct 2011;93:443-455.

[8] Huang ZQ, Nie GH, Chan CK. An exact solution for stress in cracked composite laminates and evaluation of the characteristic damage state. Compos Part B 2011;42:1008-1014.

[9] Laurin F, Carrere N, Huchette C, Maire JF. A multiscale hybrid approach for damage and final failure predictions of composite structures. J Compos Mater 2013;47:2713-47.

[10] Chamis CC, Abdi F, Garg M, Minnetyan L, Baid H, Huang D, et al. Micromechanics-based progressive failure of analysis prediction for WWFE-III composite coupon test cases. J Compos Mater 2013;47:2695-712.

[11] Berthelot JM. Transverse cracking and delamination in cross-ply glass-fiber and carbon-fiber reinforced plastic laminates: static and fatigue loading. Appl Mech Rev 2003;56:111-147.

[12] Loukil MS, Varna J, Ayadi Z. Engineering expressions for thermo-elastic constants of laminates with high density of transverse cracks. Compos Part A 2013;48:37-46.

[13] Carraro PA, Quaresimin M. A stiffness degradation model for cracked multidirectional laminates with cracks in multiple layers. Int J Solids Struct 2015;58:34-51.

[14] Highsmith AL, Reifsnider K. Stiffness-reduction mechanisms in composite laminates. In: Reifsnider K (Ed.). Damage in composite materials. ASTM STP 775, Philadelphia, pp. 103-117, 1982.

[15] Smith PA, Wood, JR. Poisson's ratio as a damage parameter in the static tensile loading of simple cross-ply laminates. Compos Sci Technol 1990;38:85-93.

[16] Tsai CL, Daniel IM. The behaviour of cracked cross-ply composite laminates under shear loading. Int J Sol Struct 1992;29:3251-3267.

[17] Zhang J, Fan J, Soutis C. Analysis of multiple matrix cracking in $\left[ \pm \theta_{\mathrm{m}} / 90_{\mathrm{n}}\right]_{\mathrm{s}}$ composite laminates part 2: development of transverse ply cracks. Composites 1992;23:299-304.

[18] Berthelot JM, Leblond P, El Mahi A, LeCorre JF. Transverse cracking of cross-ply laminates: part 1. analysis. Compos Part A 1996;27;989-1001. 
[19] Zhang J, Herrmann KP. Stiffness degradation induced by multilayer intralaminar cracking in composite laminates. Compos Part A 1999;30:683-706.

[20] Kashtalyan M, Soutis C. Stiffness degradation in cross-ply laminates damaged by transverse cracking and splitting. Compos Part A 2000;31:335-351.

[21] Mayugo JA, Camanho PP, Maimi P, Davila CG. Analytical modelling of transverse matrix cracking of $\left\{ \pm \theta / 90_{\mathrm{n}}\right\}_{\mathrm{S}}$ composite laminates under multiaxial loading. Mech Adv Mater Struct 2010;17:237-45.

[22] Kashtalyan M, Soutis C. Predicting residual stiffness of cracked composite laminates subjected to multi-axial inplane loading. J Compos Mater 2013;47:2513-24.

[23] Hashin Z. Analysis of cracked laminates: a variational approach. Mech Mater 1985;4:121-36.

[24] Vinogradov V, Hashin Z. Probablistic energy based model for prediction of transverse cracking in cross-ply laminates. Int J Solids Struct 2005;42:365-92.

[25] Liu S, Nairn JA. The formation and propagation of matrix microcracks in cross-ply laminates during static loading. J Reinf Plast Compos 1992;11:158-178.

[26] Nairn JA, Hu S. The formation and effect of outer-ply microcracks in cross-ply laminates: a variational approach. Eng Fract Mech 1992;41:203-221.

[27] McCartney LN. Predicting transverse crack formation in cross-ply laminates. Compos Sci Technol 1998;58:1069-81.

[28] Barbero EJ, Sgambitterra G, Adumitroaie A, Martinez X. A discrete constitutive model for transverse and shear damage of symmetric laminates with arbitrary stacking sequence. Compos Struct 2011;93:1021-1030.

[29] Barbero EJ, Cosso FA. Determination of material parameters for discrete damage mechanics analysis of carbon-epoxy laminates. Compos Part B 2014;56:638-646.

[30] Garcia IG, Carter BJ, Ingraffea AR, Mantic V. A numerical study of transverse cracking in cross-ply laminates by 3D finite fracture mechanics. Compos Part B 2016;95:475-487.

[31] Berthelot JM, LeCorre JF. Modelling the transverse cracking in cross-ply laminates: application to fatigue. Compos Part B 1999;30:569-577.

[32] Nairn JA, Mendels DA. On the use of planar shear-lag methods for stress transfer analysis of multilayered composites. Mech Mater 2001;33:335-362.

[33] Gudmundson P, Zang W. An analytic model for thermoelastic properties of composite laminates containing transverse matrix cracks. Int J Solids Struct 1993;30:3211-3231.

[34] Gudmundson P, Ostlund S. First order analysis of stiffness reduction due to matrix cracking. J Comput Mater 1992;26:1009-1030.

[35] Joffe R, Krasnikovs A, Varna J. COD-based simulation of transverse cracking and stiffness reduction in $\left[\mathrm{S} / 90_{n}\right]_{\mathrm{s}}$ laminates. Compos Sci Technol 2001;61:637-56.

[36] Lundmark P, Varna J. Crack face sliding effect on stiffness of laminates with ply cracks. Compos Sci Technol 2006;66:1444-1454.

[37] Singh CV, Talreja R. A synergistic damage mechanics approach for composite laminates with matrix cracks in multiple orientations. Mech Mater 2009;41:954-68.

[38] Singh CV, Talreja R. Evolution of ply cracks in multidirectional composite laminates. Int J Solids Struct 2010;47:1338-49.

[39] Ghayour M, Hosseini-Toudeshky H, Jalalvand M, Barbero EJ. Micro/macro approach for prediction of matrix cracking evolution in laminated composites. J Compos Mater 2015;50:2647-59.

[40] Akula VMK, Garnich MR. Effective ply and constituent elastic properties for cracked laminates. Compos Part B 2012;43:2143-2151.

[41] Noh J, Whitcomb JD. Effect of various parameters on the effective properties of a cracked ply. J Compos Mater 2001;35:689-712.

[42] Pineda EJ, Waas AM. Numerical implementation of a multiple-ISV thermodynamically-based work potential theory for modeling progressive damage and failure in fiber-reinforced laminates. Int $\mathbf{J}$ Fract 2013;182:93-122.

[43] Santhosh U, Ahmad J, Ojard G, Miller R, Gowayed Y. Deformation and damage modeling of ceramic matrix composites under multiaxial stresses. Compos Part B 2016;90:97-106 
[44] Montesano J, Singh CV. Predicting evolution of ply cracks in composite laminates subjected to biaxial loading. Compos Part B 2015;75:264-273.

[45] Montesano J, Singh CV. Critical stiffness damage envelopes for multidirectional laminated structures under multiaxial loading conditions. Mater Design 2016;91:218-229.

[46] Montesano J, Chu H, Singh CV. Development of a physics-based multi-scale progressive damage model for assessing the durability of wind turbine blades. Compos Struct 2016;141:50-62.

[47] D'Ottavio M, Vidal P, Valot E, Polit O. Assessment of plate theories for free-edge effects. Compos Part B 2013;48:111-121.

[48] Islam MS, Prabhakar P. Modeling framework for free edge effects in laminates under thermomechanical loading. Compos Part B 2017;116:89-98.

[49] Talreja R. Damage characterization by internal variables. In: Talreja R, editor. Damage Mechanics of Composite Materials. Amsterdam: Elsevier, 1994. p. 53-78.

[50] Fan J, Zhang J. In-situ damage evolution and micro/macro transition for laminated composites. Compos Sci Technol 1993;47:107-118.

[51] Varna J. Physical interpretation of parameters in synergistic continuum damage mechanics model for laminates. Compos Sci Technol 2008;68:2592-2600.

\section{Figures}

Fig. 1. Schematic of hierarchical damage-based multiscale modeling approach.

Fig. 2. Representative volume element of a general symmetric multidirectional laminate with cracking in multiple plies, subjected to an in-plane multiaxial stress state.

Fig. 3. 3D meso-mechanical FE model for a quasi-isotropic laminate containing cracks in multiple plies, with variable crack densities, subjected to multiaxial strains. A schematic of the cracked and adjacent ply thicknesses are also shown.

Fig. 4. Variation of normalized crack displacements with crack density for different plies in a $[0 / 90 / \mp$ 45] $]_{\mathrm{s}}$ laminate with $0.5 \mathrm{~mm}$ constant ply thickness: (a) COD, (b) CSD.

Fig. 5. $[0 / 90 / \mp 45]_{\mathrm{s}}$ laminate (L01): (a) $0^{\circ}$ ply normalized CSD variation with crack density, (b) $90^{\circ}$ ply normalized COD variation with crack density for indicated stress states.

Fig. 6. Normalized (a) COD, and (b) CSD profiles for $90^{\circ}$ plies of indicated cross-ply laminates. Note that the solid lines represent the analytical model predictions, while the symbols represent data from the meso-mechanical FE simulations.

Fig. 7. Normalized (a) COD, and (b) CSD profiles of indicated plies for laminate L09. Note that the solid lines represent the analytical model predictions, while the symbols represent data from the mesomechanical FE simulations.

Fig. 8. Normalized crack surface displacement profiles for indicated plies: (a) L01 COD, (b) L01 CSD, (c) L01 and L03 COD, (d) L04 CSD. Note that the solid lines represent the analytical model predictions, while the symbols represent data from the meso-mechanical FE simulations.

Fig. 9. Normalized properties vs. crack density for $[0 / 90]_{\mathrm{s}}$ and $\left[0 / 90_{2}\right]_{\mathrm{S}}$ GFRP and $[0 / 90]_{\mathrm{s}}$ CFRP laminates containing $90^{\circ}$ ply cracks: (a) $E_{x} / E_{x}{ }^{o}$, (b) $v_{x y} / v_{x y}{ }^{\circ}$, and (c) $G_{x y} / G_{x y}{ }^{\circ}$. The symbols represent FE data, solid lines model predictions, and dashed lines ply discount approximations.

Fig. 10. Normalized properties vs. crack density for [0/90/ 45] $]_{\mathrm{s}}$ GFRP and CFRP laminates containing $90^{\circ}$ ply cracks: (a) $E_{x} / E_{x}{ }^{o}$, (b) $v_{x y} / v_{x y}{ }^{o}$, and (c) $G_{x y} / G_{x y}{ }^{o}$. The symbols represent FE data, solid lines model predictions, and dashed lines ply discount approximations.

Fig. 11. Normalized properties vs. crack density for $[0 / 90]_{\mathrm{s}}$ GFRP laminate containing both $90^{\circ}$ and $0^{\circ}$ ply cracks with the same density: (a) $E_{x} / E_{x}{ }^{o}$ and $v_{x y} / v_{x y}{ }^{o}$, (b) $E_{y} / E_{y}{ }^{o}$ and $G_{x y} / G_{x y}{ }^{o}$. The symbols represent FE data and solid lines model predictions. 
Fig. 12. Normalized properties vs. crack density for $[0 / 90 / \mp 45]_{\mathrm{s}}$ GFRP laminate containing $90^{\circ},+45^{\circ}$ and $-45^{\circ}$ ply cracks with indicated density: (a) $E_{x} / E_{x}{ }^{o}$ and $v_{x y} / v_{x y}{ }^{o}$, (b) $E_{y} / E_{y}{ }^{o}$ and $G_{x y} / G_{x y}{ }^{o}$. The symbols represent FE data and solid lines model predictions.

Fig. 13. Normalized properties vs. crack density for $[ \pm 45]_{\mathrm{s}}$ GFRP laminate containing $\pm 45^{\circ}$ ply cracks with indicated density: (a) $E_{x} / E_{x}{ }^{o}$ and $v_{x y} / v_{x y}{ }^{o}$, (b) $E_{y} / E_{y}{ }^{o}$ and $G_{x y} / G_{x y}{ }^{o}$. The symbols represent FE data and solid lines model predictions.

Fig. 14. Crack density evolution in $90^{\circ}$ plies under uniaxial quasi-static tensile load for (a) $[0 / 90]_{\mathrm{S}} \mathrm{CFRP}$ laminate (L07), and (b) $\left[0 / 90_{2}\right]_{\mathrm{s}}$ CFRP laminate (L08). The symbols represent experimental data from Ref. [17] and solid lines model predictions.

Fig. 15. Crack density evolution under uniaxial quasi-static tensile load for (a) [0/90] $]_{\mathrm{s}}$ GFRP (L05), and (b) $[0 / 90 / \mp 45]_{\mathrm{s}}$ GFRP (L01). The symbols represent experimental data from Ref. [2] and solid lines model predictions.

\section{Tables}

Table 1. Laminate description and corresponding ply properties.

\begin{tabular}{|c|c|c|c|c|c|c|c|c|c|}
\hline \multirow[b]{2}{*}{$\begin{array}{l}\text { Laminate } \\
\text { ID }\end{array}$} & \multirow[b]{2}{*}{$\begin{array}{l}\text { Stacking } \\
\text { Sequence }\end{array}$} & \multicolumn{8}{|c|}{ Ply Properties } \\
\hline & & Material & $\begin{array}{c}E_{1} \\
(\mathrm{GPa})\end{array}$ & $\begin{array}{c}E_{2} \\
(\mathrm{GPa})\end{array}$ & $\begin{array}{c}G_{12} \\
(\mathrm{GPa})\end{array}$ & $\begin{array}{c}G_{23} \\
(\mathrm{GPa})\end{array}$ & $v_{12}$ & $v_{23}$ & $\begin{array}{c}\mathrm{t}_{\mathrm{ply}} \\
(\mathrm{mm})\end{array}$ \\
\hline L01 & {$[0 / 90 / \mp 45]_{\mathrm{s}}$} & GFRP & 46 & 13 & 5 & 4.3 & 0.30 & 0.40 & 0.50 \\
\hline L02 & {$[0 / 90 / \mp 45]_{\mathrm{s}}$} & GFRP & 46 & 13 & 5 & 4.3 & 0.30 & 0.40 & 0.25 \\
\hline L03 & {$[0 / 90 / \mp 45]_{\mathrm{s}}$} & CFRP & 173 & 10 & 6.9 & 3.4 & 0.33 & 0.49 & 0.50 \\
\hline L04 & {$[0 / \mp 45 / 90]_{\mathrm{s}}$} & GFRP & 46 & 13 & 5 & 4.3 & 0.30 & 0.40 & 0.50 \\
\hline L05 & {$[0 / 90]_{\mathrm{s}}$} & GFRP & 46 & 13 & 5 & 4.3 & 0.30 & 0.40 & 0.50 \\
\hline L06 & {$\left[0 / 90_{2}\right]_{\mathrm{s}}$} & GFRP & 46 & 13 & 5 & 4.3 & 0.30 & 0.40 & 0.50 \\
\hline L07 & {$[0 / 90]_{\mathrm{s}}$} & CFRP & 145 & 11.4 & 6.5 & 4.3 & 0.30 & 0.40 & 0.132 \\
\hline L08 & {$\left[0 / 90_{2}\right]_{\mathrm{s}}$} & CFRP & 145 & 11.4 & 6.5 & 4.3 & 0.30 & 0.40 & 0.132 \\
\hline L09 & {$[ \pm 45]_{\mathrm{s}}$} & GFRP & 45.6 & 16.2 & 5.8 & 5.7 & 0.28 & 0.40 & 0.50 \\
\hline $\mathrm{L} 10$ & {$[ \pm 45]_{\mathrm{s}}$} & GFRP & 45.6 & 16.2 & 5.8 & 5.7 & 0.28 & 0.40 & 0.25 \\
\hline
\end{tabular}




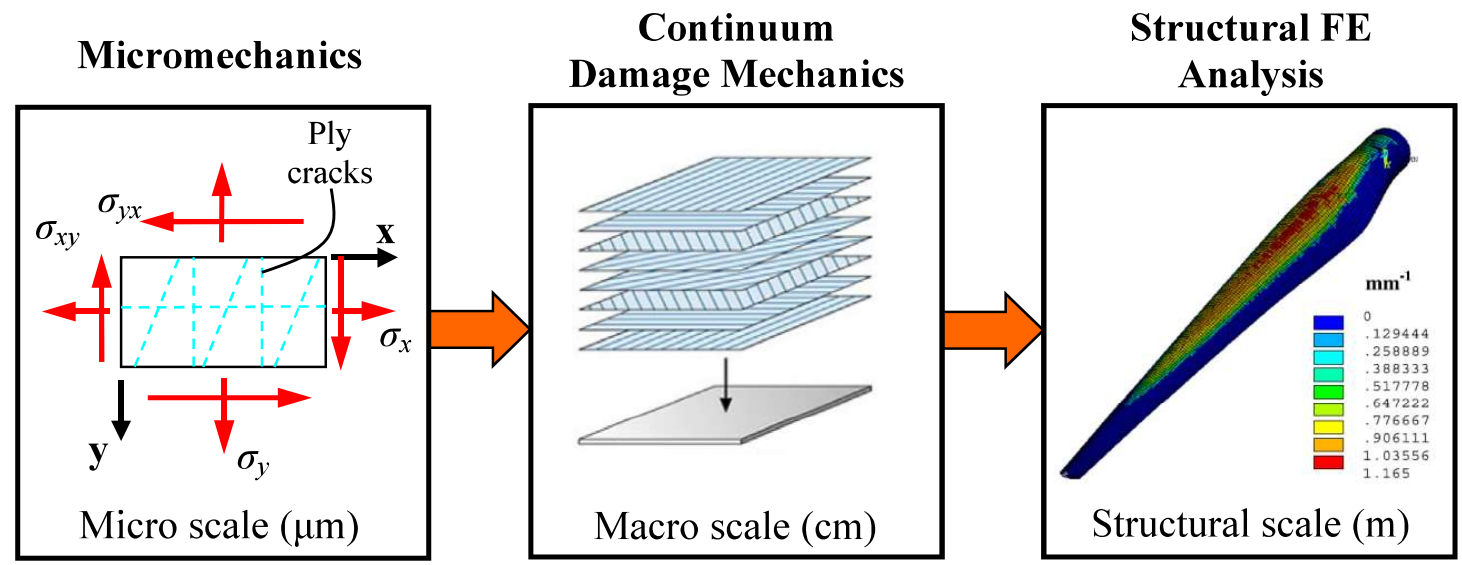




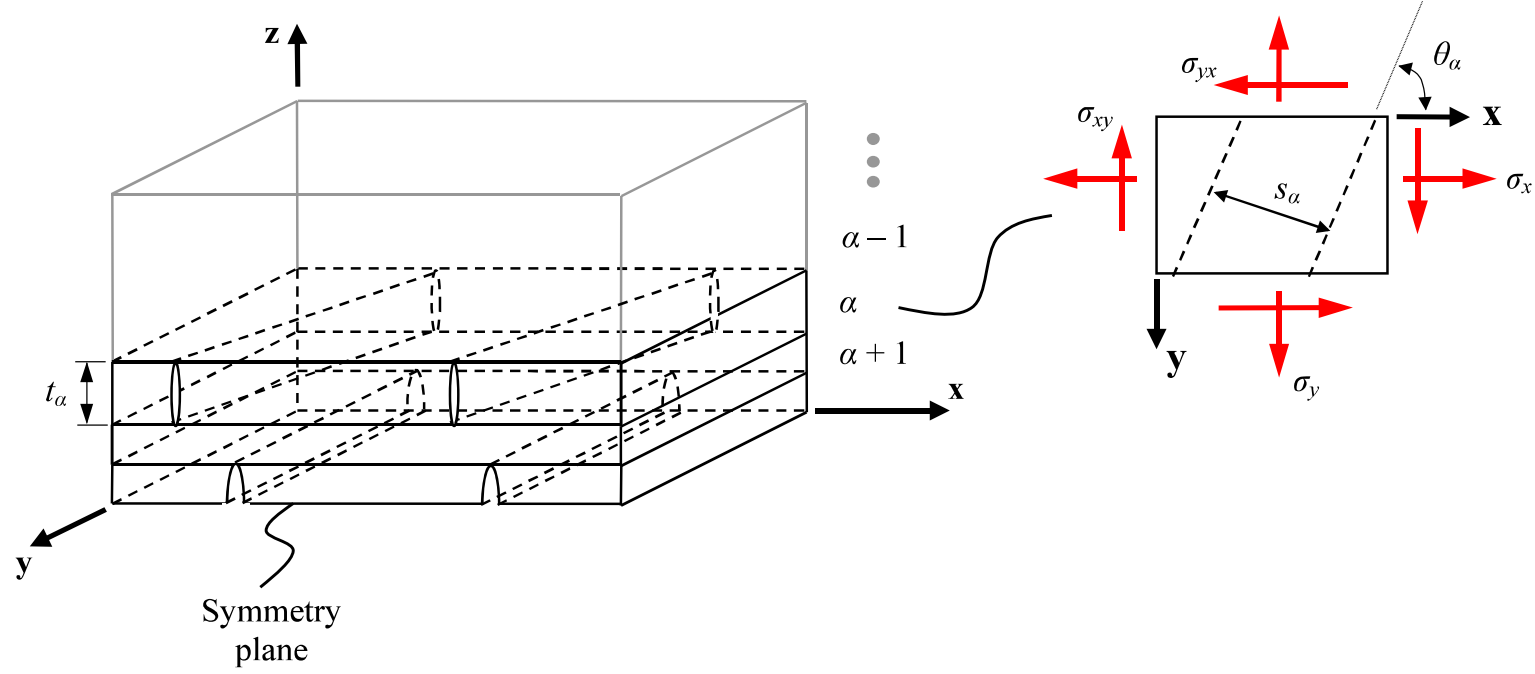




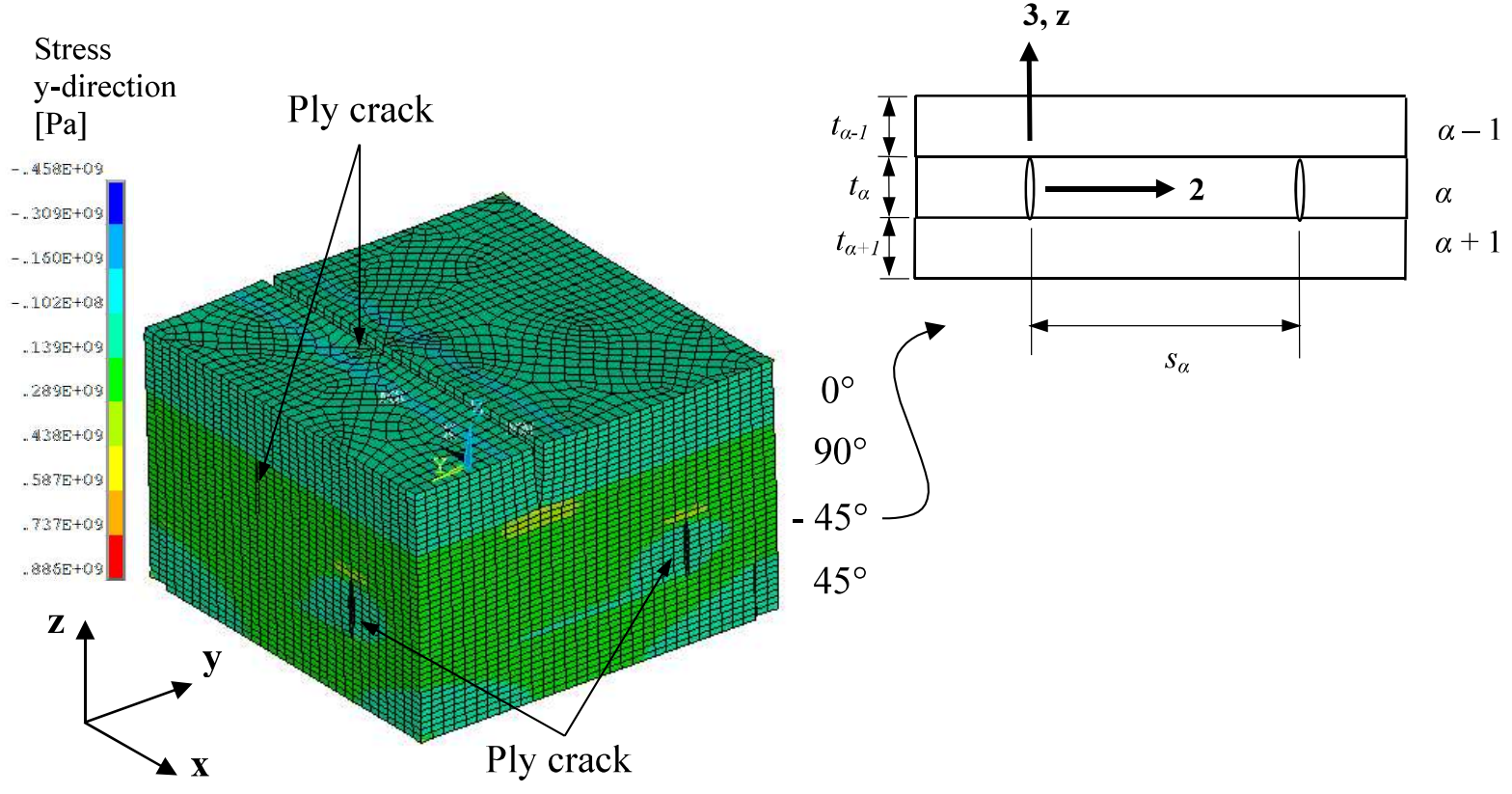


(a)

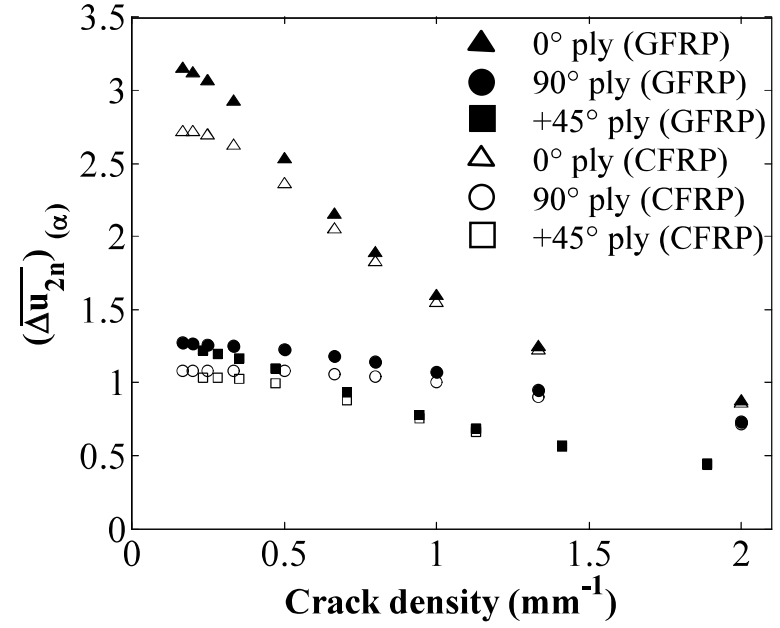

(b)

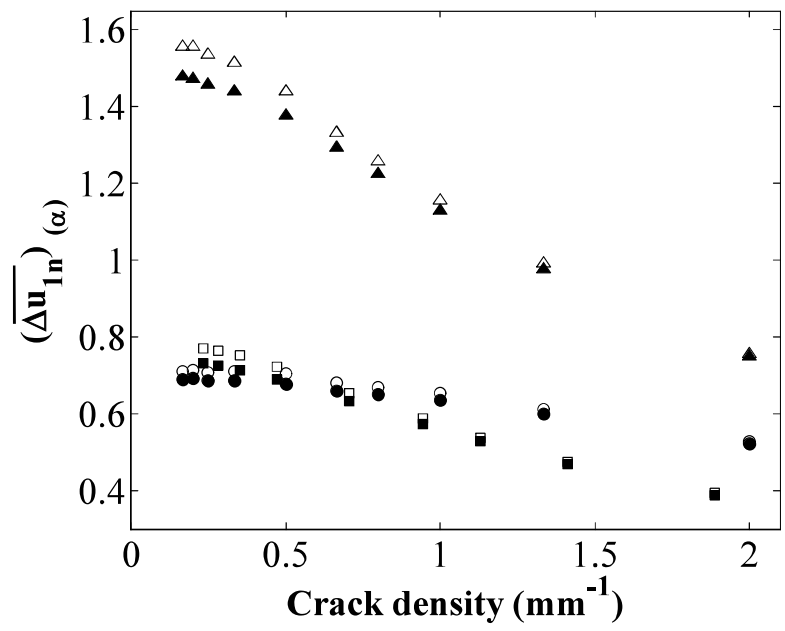


(a)

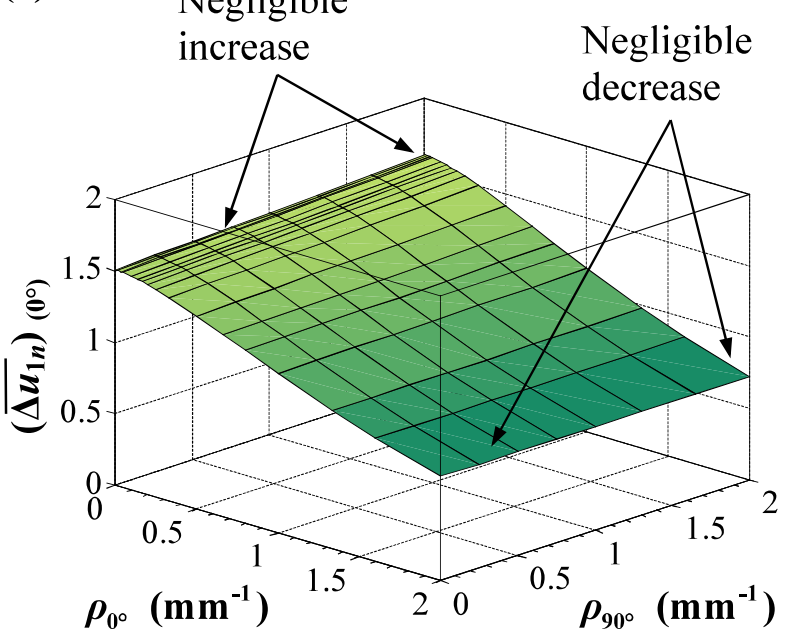

(b)

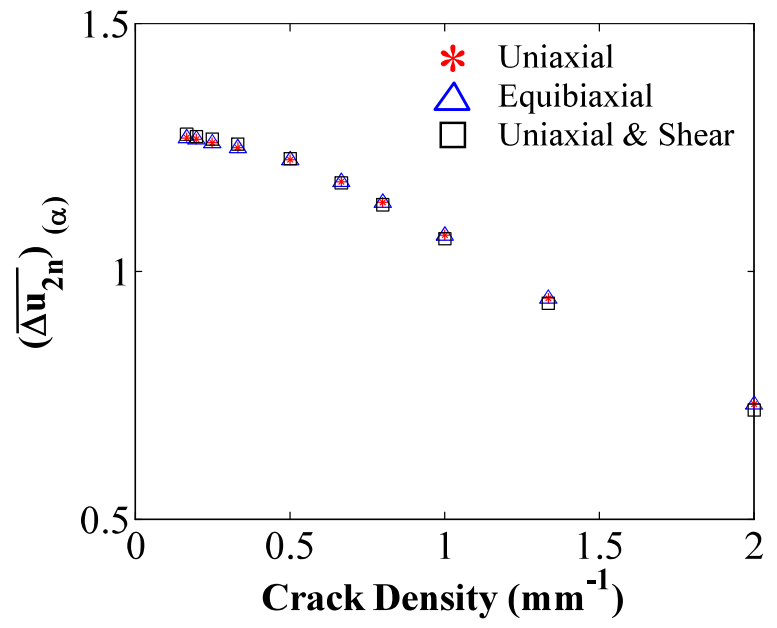


(a)

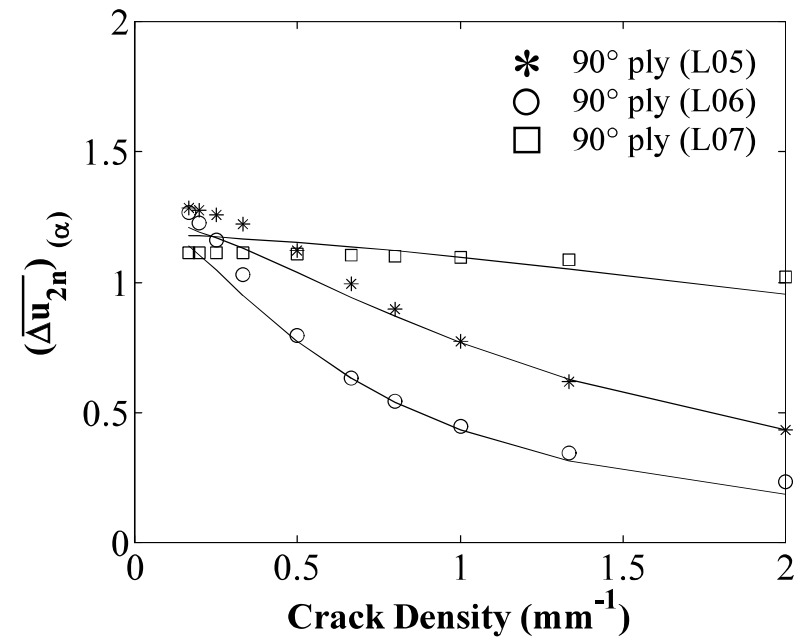

(b)

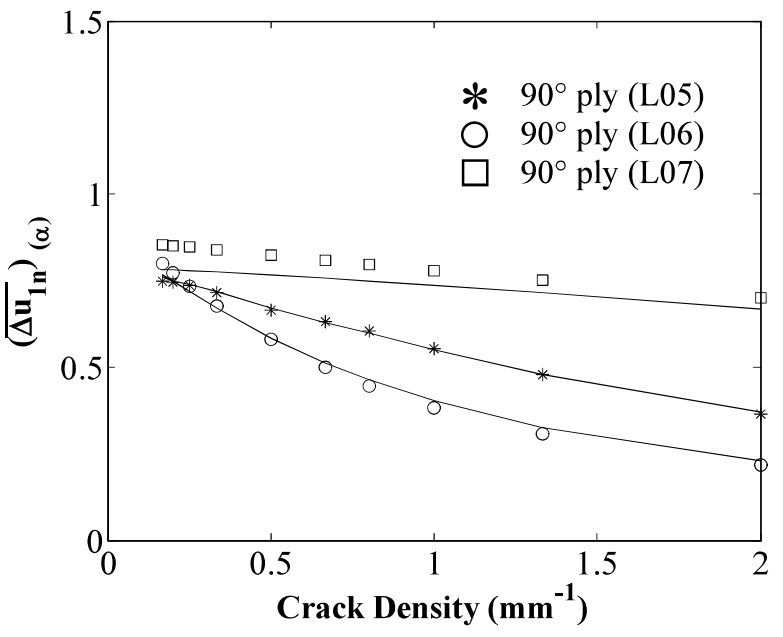


(a)

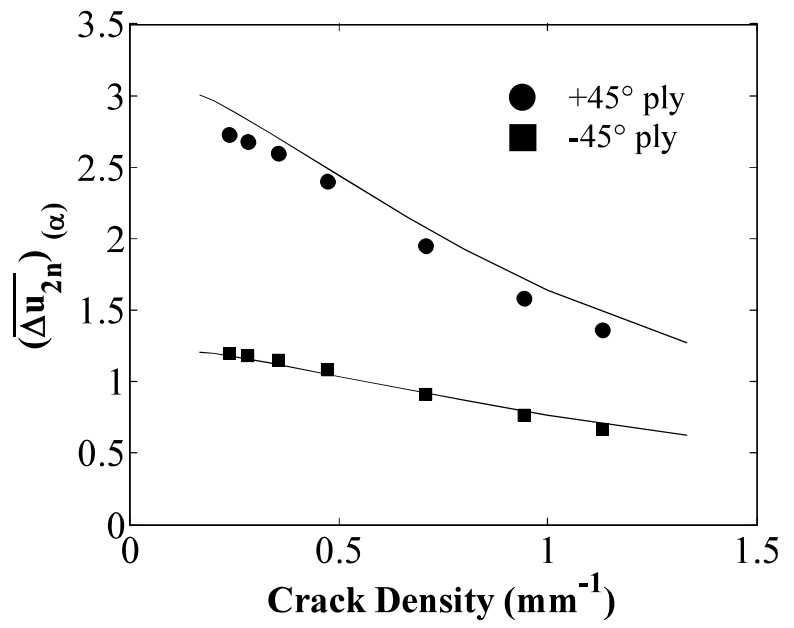

(b)

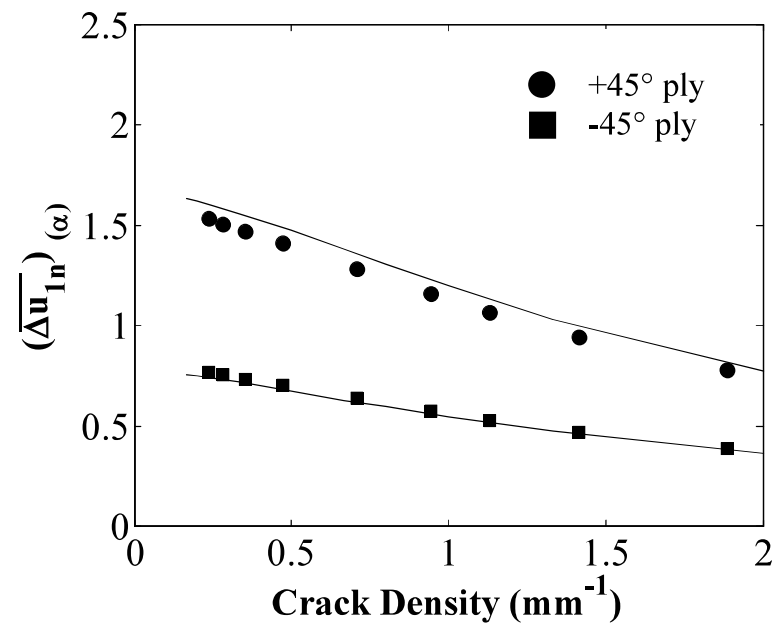


(a)

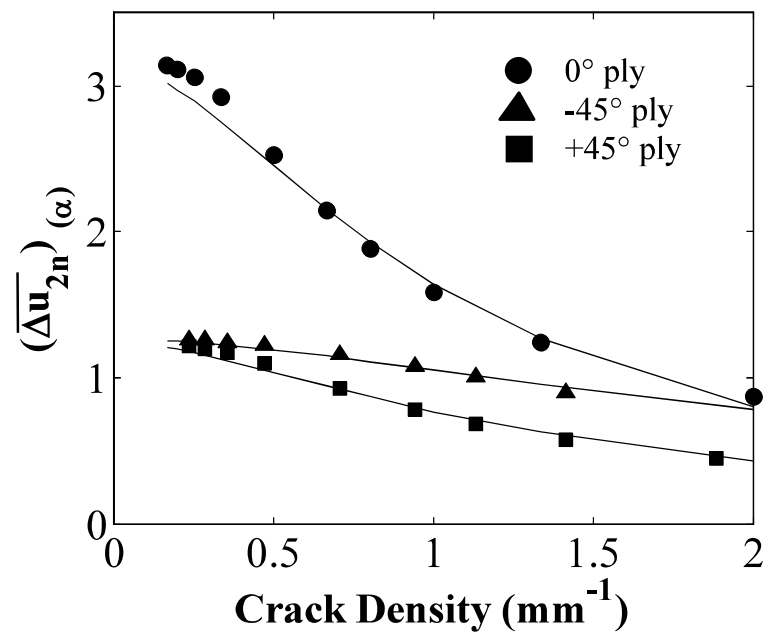

(c)

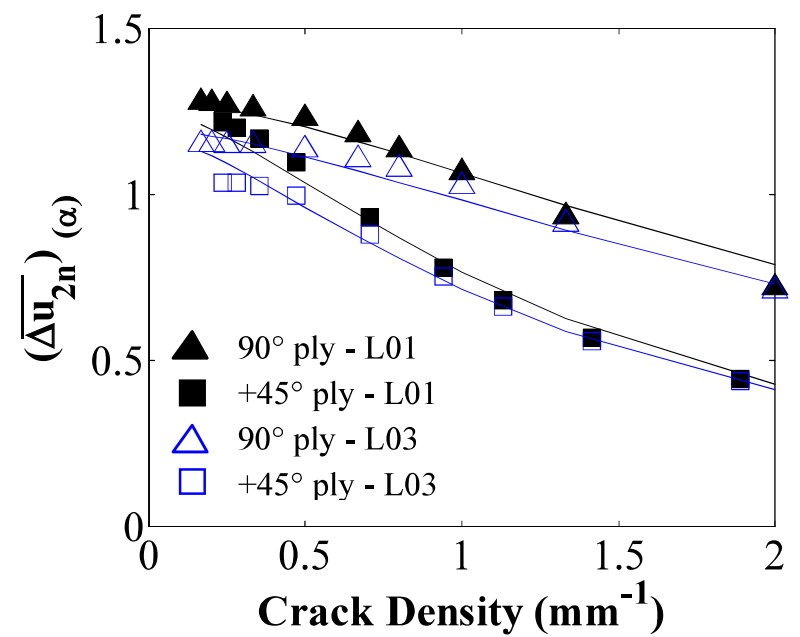

(b)

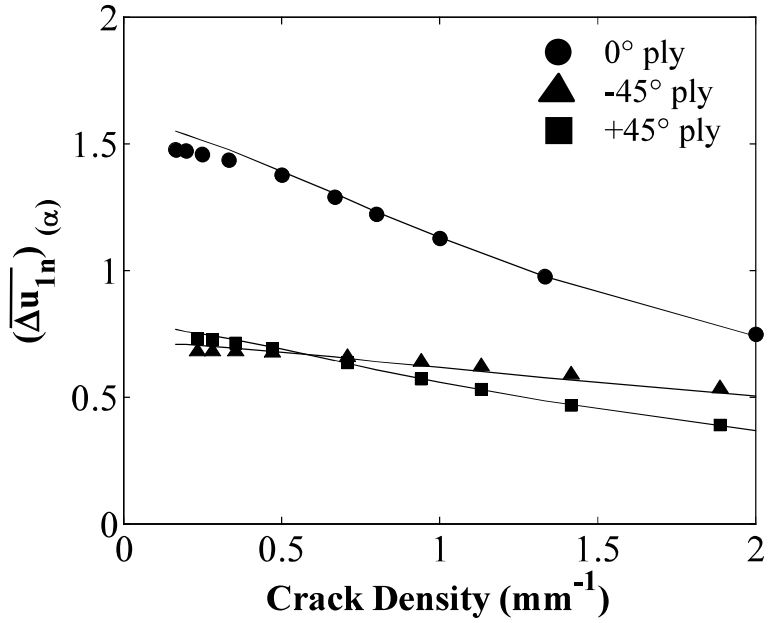

(d)

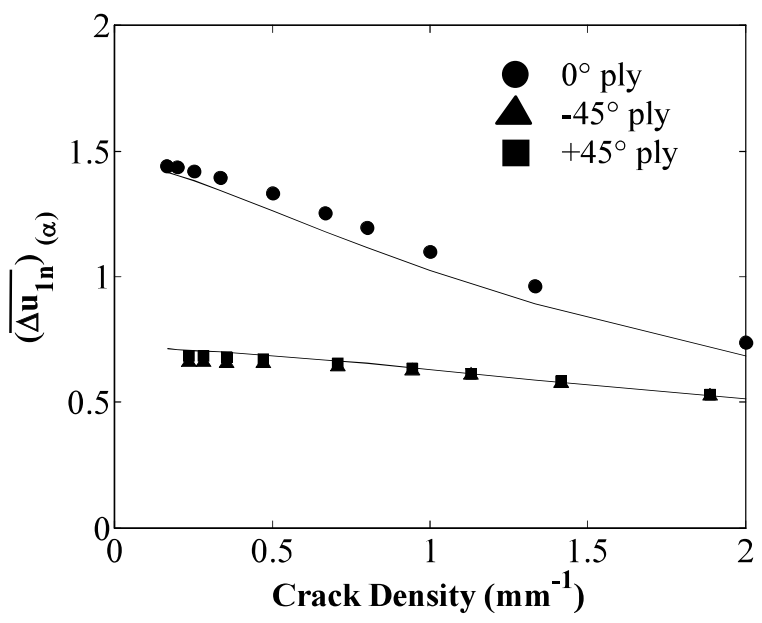


(a)

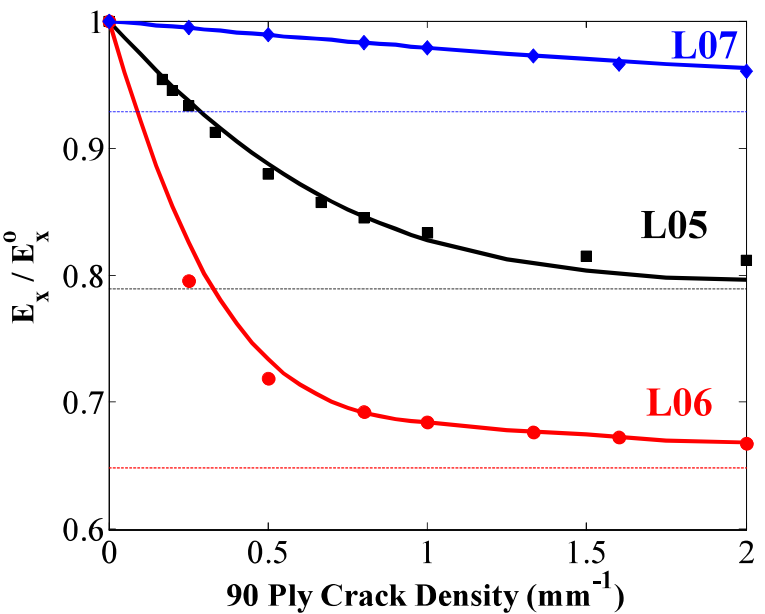

(c)

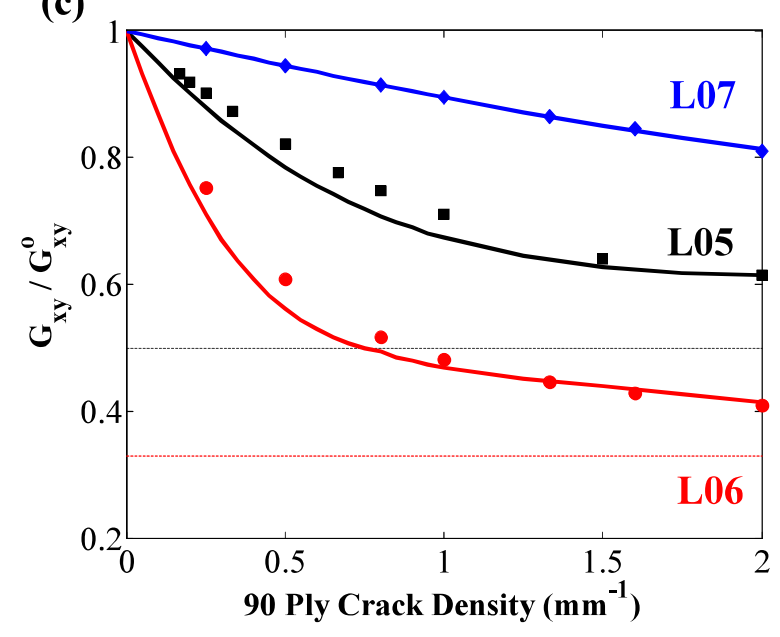

(b)

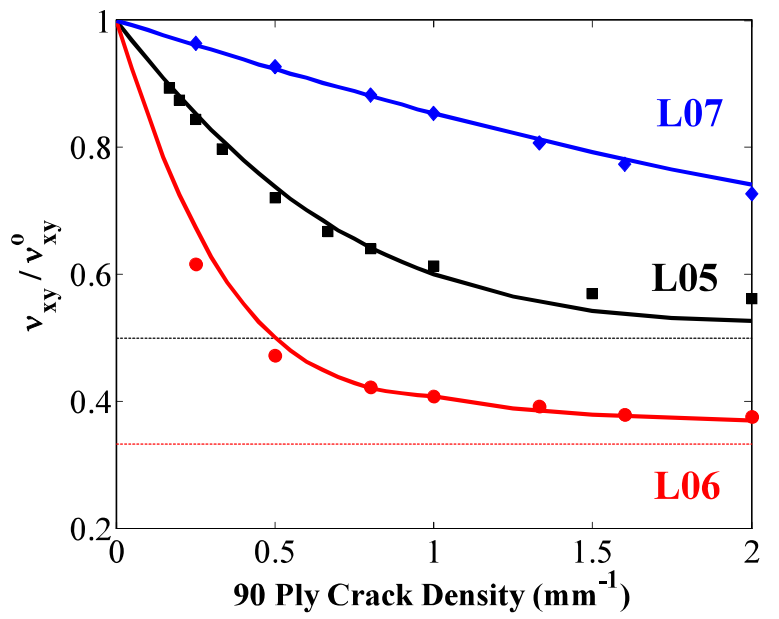


(a)

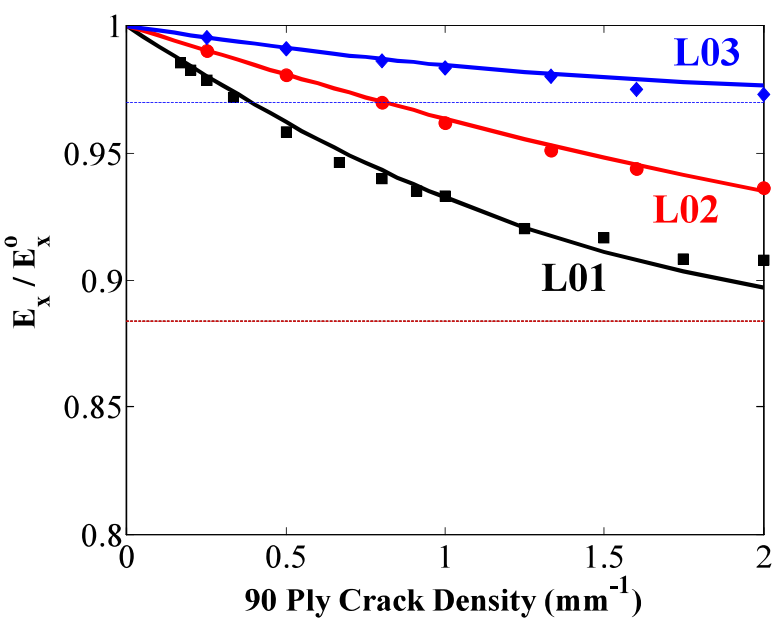

(c)

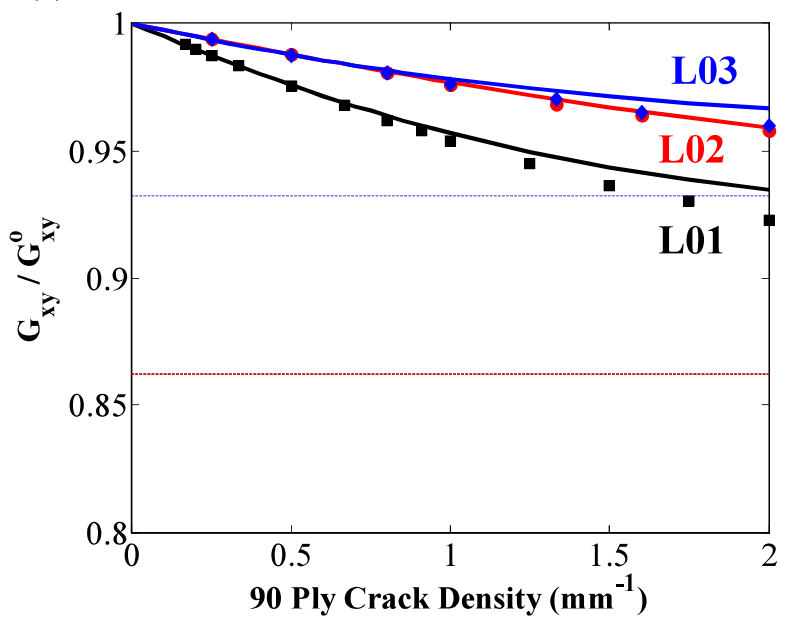

(b)

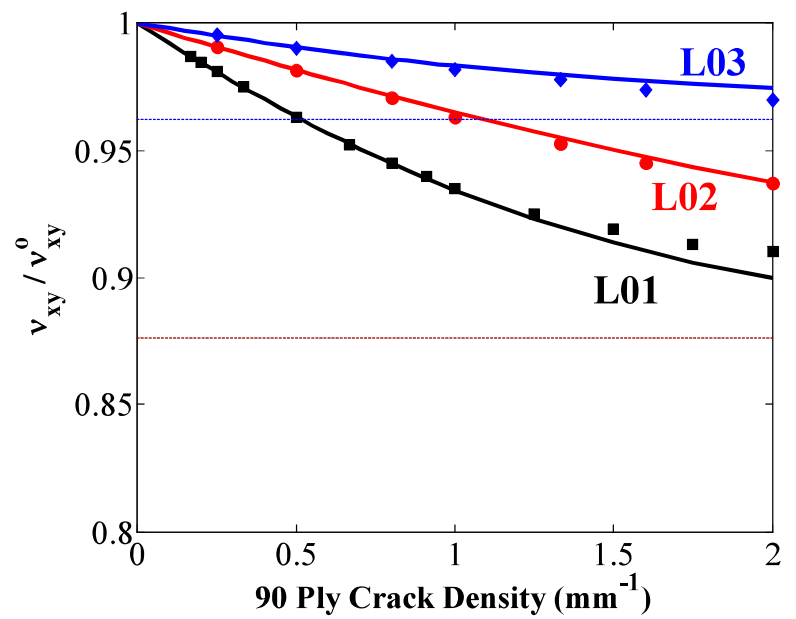


(a)

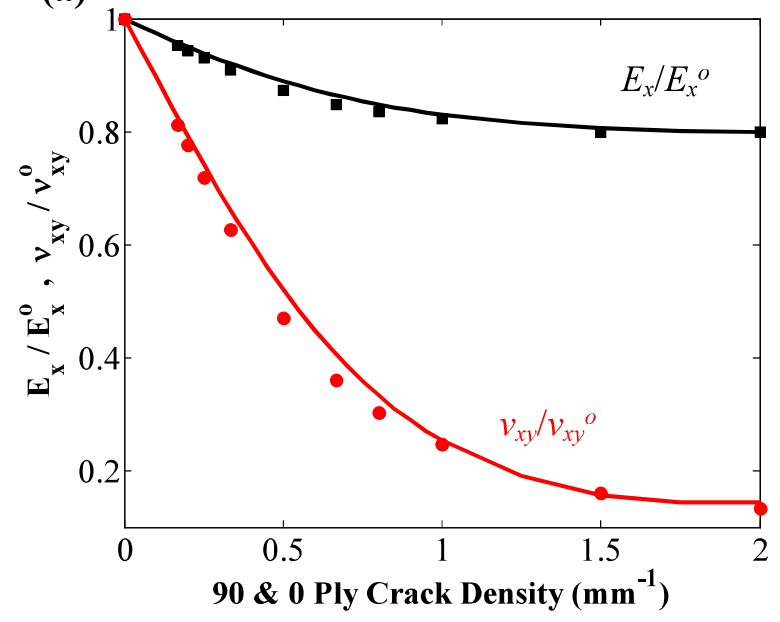

(b)

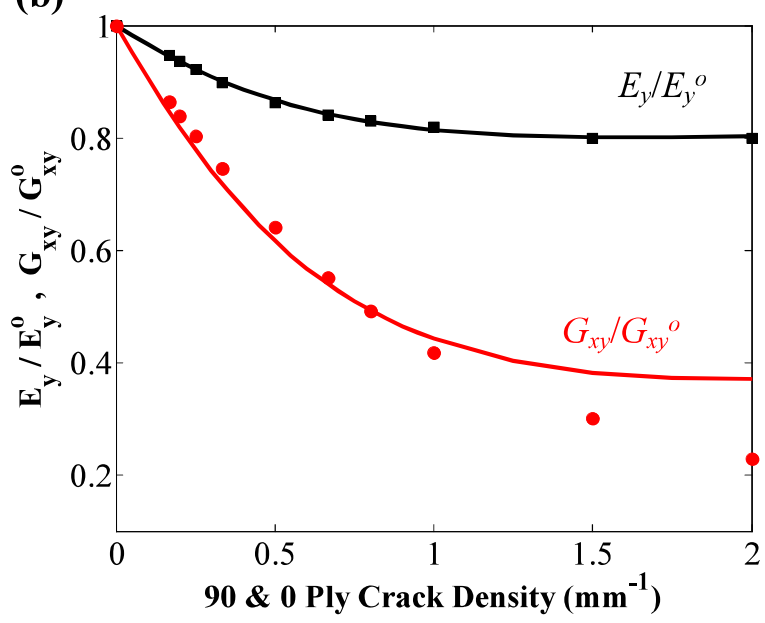


(a)

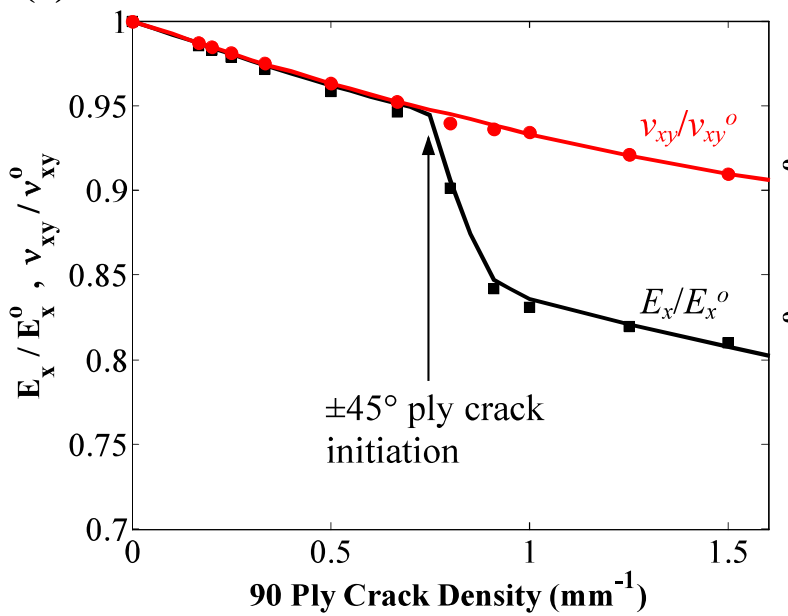

$\begin{array}{cc}\frac{1}{0} & 0.5 \\ +/-45 & \text { Ply Crack Density }\left(\mathrm{mm}^{-1}\right)\end{array}$ (b)
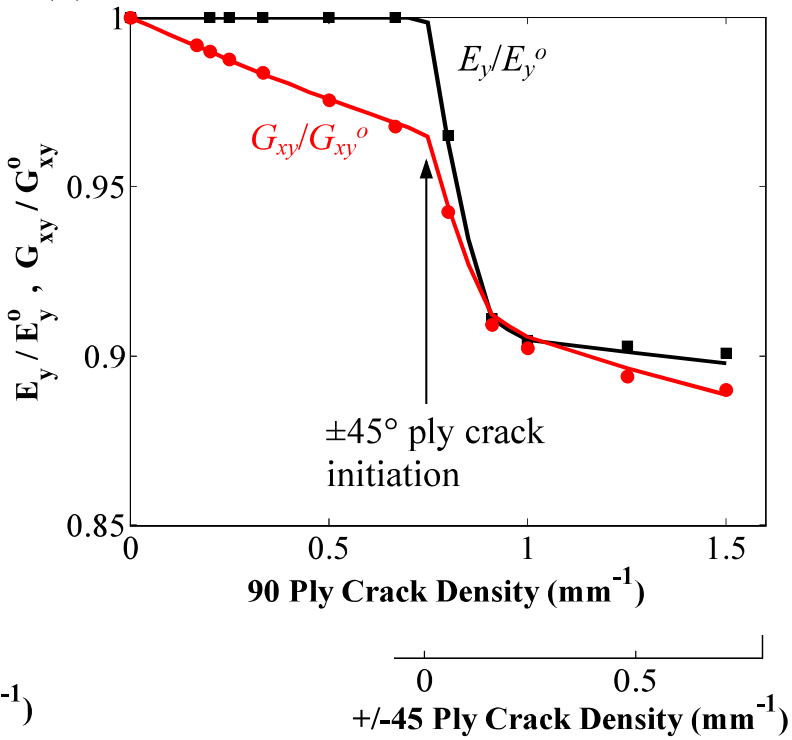
(a)

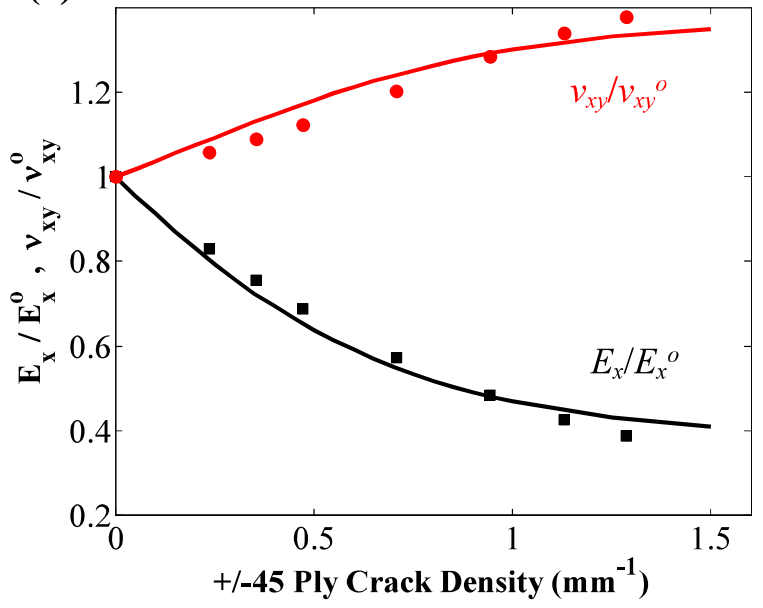

(b)

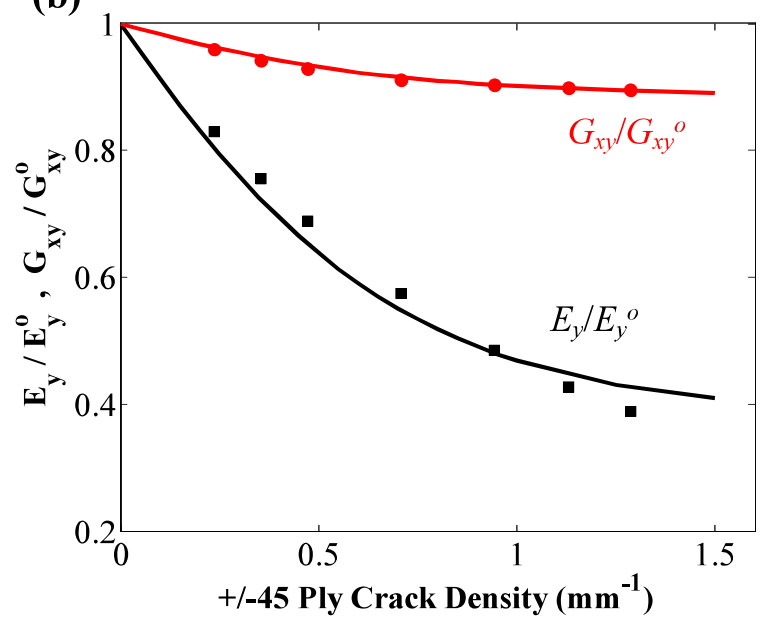


(a)

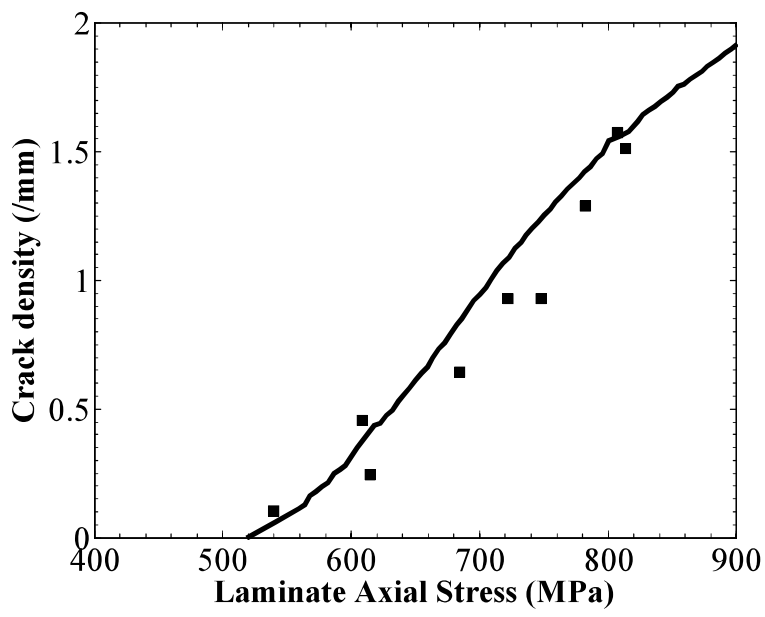

(b)

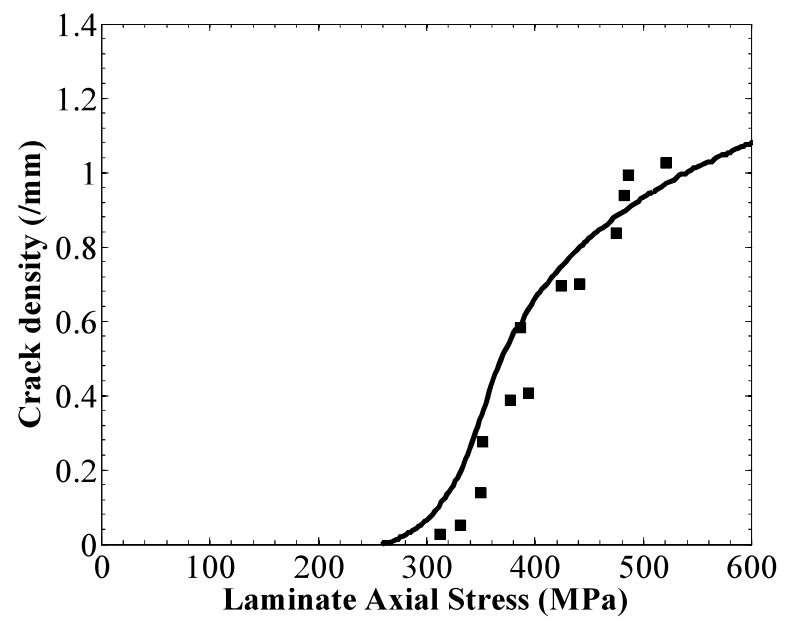


(a)

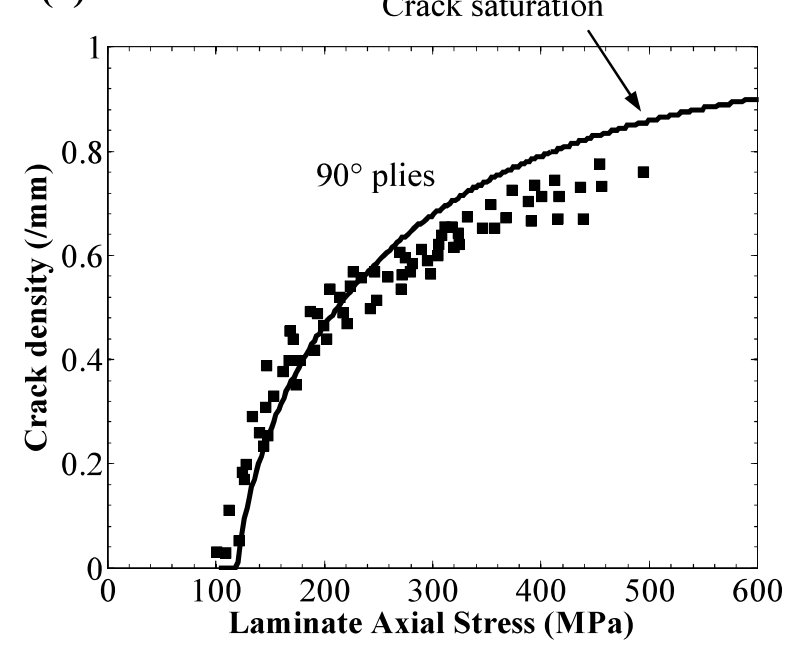

(b) Crack saturation

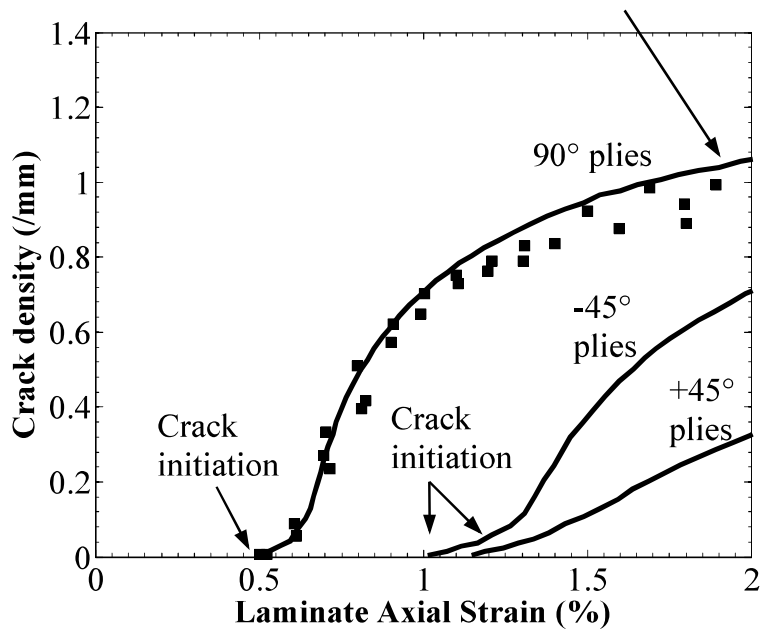

